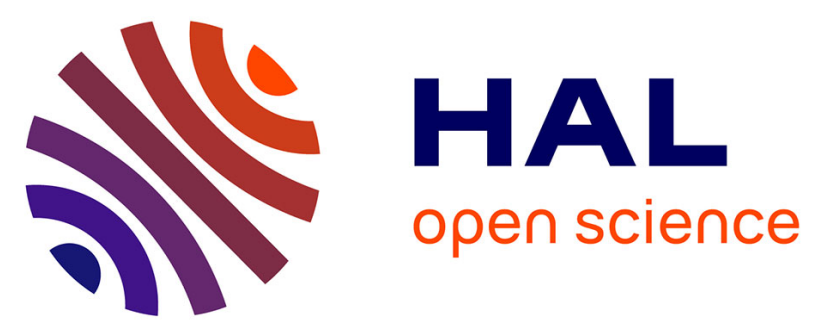

\title{
The wake south of the Alps: dynamics and structure of the lee-side flox and secondary potential vorticity banners
}

\author{
Cyrille Flamant, E. Richard, C. Schär, R. Rotunno, L. Nance, M. Sprenger, \\ R. Benoît
}

\section{To cite this version:}

Cyrille Flamant, E. Richard, C. Schär, R. Rotunno, L. Nance, et al.. The wake south of the Alps: dynamics and structure of the lee-side flox and secondary potential vorticity banners. Quarterly Journal of the Royal Meteorological Society, 2004, 130 (599), pp.1275-1303. 10.1256/qj.03.17 . hal00141848

\section{HAL Id: hal-00141848 \\ https://hal.science/hal-00141848}

Submitted on 7 Jul 2021

HAL is a multi-disciplinary open access archive for the deposit and dissemination of scientific research documents, whether they are published or not. The documents may come from teaching and research institutions in France or abroad, or from public or private research centers.
L'archive ouverte pluridisciplinaire HAL, est destinée au dépôt et à la diffusion de documents scientifiques de niveau recherche, publiés ou non, émanant des établissements d'enseignement et de recherche français ou étrangers, des laboratoires publics ou privés. 


\title{
The wake south of the Alps: Dynamics and structure of the lee-side flow and secondary potential vorticity banners
}

\author{
By C. FLAMANT $^{1 *}$, E. RICHARD ${ }^{2}$, C. SCHÄR ${ }^{3}$, R. ROTUNNO ${ }^{4}$, \\ L. NANCE ${ }^{5,6}$, M. SPRENGER ${ }^{3}$ and R. BENOIT ${ }^{7}$ \\ ${ }^{1}$ Institut Pierre-Simon Laplace, Paris, France \\ ${ }^{2}$ Laboratoire d'Aérologie, Toulouse, France \\ ${ }^{3}$ Atmospheric and Climate Science ETH, Zurich, Switzerland \\ ${ }^{4}$ National Center for Atmospheric Research, Boulder, USA \\ ${ }^{5}$ National Oceanic and Atmospheric Administration, Boulder, USA \\ ${ }^{6}$ University of Colorado, Boulder, USA \\ ${ }^{7}$ Recherche en Prévision Numérique, Dorval, Canada
}

\begin{abstract}
SUMMARY
The dynamics and structure of the lee-side flow over the Po valley during a northerly föhn event, which occurred in the framework of the Mesoscale Alpine Programme Special Observation Period (on 8 November 1999 during Intensive Observation Period 15), has been investigated using aircraft data and high-resolution numerical simulations. Numerical simulations were performed with the mesoscale non-hydrostatic model Meso- $\mathrm{NH}$, using three nested domains (with horizontal resolutions 32,8 and $2 \mathrm{~km}$ ), the $2 \mathrm{~km}$ resolution domain being centred on the Po valley. The basic data-model comparison, and back-trajectory and tracer release analyses, provided evidence that the jet/wake structure of the flow above the Po valley could be reasonably identified with the mountain pass/peak distributions. Measurements from three aircraft flying below the Alps crestline (at 2700, 1500 and $600 \mathrm{~m}$ above sea level) along two $350 \mathrm{~km}$ east-west legs, designed to be approximately perpendicular to the northerly synoptic flow, were used to compute the potential vorticity (PV) experimentally assuming the lee-side flow to be two-dimensional. (The simplified form of the PV under these assumptions is hereafter referred to as SPV). Due to increasing lee-side flow curvature with decreasing altitude (caused by flow splitting at the scale of the Alps), the experimentally derived SPV was compared to its simulated counterpart. In situ measurements showed that coherent secondary PV banners (PVB2s) do exist downstream of the complex Alpine terrain, as observations show oscillations between positive and negative values of SPV as expected from the simulations. The details of the structure of the SPV field simulated with Meso-NH were found to be different from the observations (i.e. the location of observed maxima and minima of SPV did not match their simulated counterparts at particular points). This is because the correspondence between observed and modelled velocity and potential temperature fields was not good enough to expect good correspondence between differentiated quantities such as vorticity and potential temperature gradient (since less-reliable shorter-scale features are thereby accentuated). Parametrized processes such as surface drag and internal diffusion, and 'numerical' processes, such as model filters, to which PV production mechanisms are sensitive and whose role is difficult to assess, also contribute to the poor agreement between observed and modelled SPV fluctuations. Finally, simulations suggest that lowlevel gravity-wave breaking was the main mechanism responsible for the formation of the elongated PVB2 modelled/observed over the Po valley.
\end{abstract}

KEYWORDS: Aircraft measurements Atmospheric boundary layer Meso-NH model Mesoscale Alpine Programme North föhn

\section{INTRODUCTION}

The idea that dissipative processes associated with flow past high mountains could alter the potential vorticity (PV) of a stratified atmosphere was first suggested on theoretical grounds a little over ten years ago (Smith 1989a,b). As the horizontal resolution of numerical models has increased over the past five years, PV banners have become a ubiquitous feature of numerical simulations of flow in complex terrain. The predicted distribution of PV downstream of a complex mountain barrier oriented perpendicular to the large-scale flow can resemble a series of smoke plumes extending downstream from several point sources (Äbischer and Schär 1998). Thus, the term

\footnotetext{
* Corresponding author: Service d'Aéronomie du CNRS, Institut Pierre-Simon Laplace, Tour 15, Boîte 102, Université Pierre et Marie Curie, 4 Place Jussieu, 75252 Paris Cedex 05, France.

e-mail: cyrille.flamant@aero.jussieu.fr
} 
plume or 'banner' is used to describe this feature. PV is conserved in the absence of diabatic and dissipative processes. PV generation requires the violation of PV conservation and, under conditions of dry flow, this is related to dissipation, either in the boundary layer or in the recirculating wake, or due to internal dissipation via a wave-breaking region. Detailed discussions of these PV generation mechanisms can be found in Schär and Durran (1997) and Smith et al. (1997). PV can also occur through the tilting of baroclinically generated vorticity and subsequent dissipation as suggested by Rotunno et al. (1999). Thus, mountain-generated PV has the potential to represent a physical link between mesoscale mountain disturbances and the largerscale balanced flow. On the other hand, the widths of the PV banners (PVBs) seem to be mainly determined by the model resolution, raising some concern that these banners may be spurious features of the numerical simulations. Although observational evidence indicates that elongated banners of modified flow can be created as stratified flow encounters isolated mountains or islands, such as Hawaii or St Vincent in the Lesser Antilles (Smith and Grubisić 1993; Smith et al. 1997), no systematic observations have been made to confirm or refute their existence in the lee of major continental mountain ranges.

The Alps, with their compact structure and irregular ridge line, provide an ideal testing ground for mountain-generated PVBs. The Mesoscale Alpine Programme (MAP) is a coordinated international effort to explore the mesoscale effects of complex terrain (Bougeault et al. 2001). The Special Observing Period (SOP) of MAP, which took place between 7 September and 15 November 1999, was organized into eight Scientific Projects. The main objectives of the PV banner project of MAP are to verify the existence of PVBs, to determine the high-resolution structure and temporal evolution of the Alpine wake and its associated PVBs, to identify the key processes responsible for the generation of PVBs, and to assess the ability of current atmospheric models to appropriately predict PVBs and their associated three-dimensional (3D) circulations (Binder and Schär 1996; Bougeault et al. 1998, 2001). During the SOP of MAP, the PVB project had four aircraft available for missions around the Alps: the National Oceanic and Atmospheric Administration (NOAA) P-3, the National Center for Atmospheric Research (NCAR) Electra, the Météo-France Merlin IV, and the multi-agency (Centre National de Recherche Scientifique, Centre National d'Études Spatiales, Institut Geographique National, Météo-France) Fokker 27 (further referred to as the ARAT). An overview of the aircraft missions dedicated to the PVB project of MAP can be found in Nance et al. (2000) and Bougeault et al. (2001).

Individual pairs of PVBs with anomalously positive and negative values of PV can be attributed to individual flow-splitting events, either on the scale of the whole Alps or on that of individual massifs and peaks. A useful distinction was made between the primary banners emanating from the eastern and western ends of the Alpine chain and the secondary banners emanating from individual peaks along the irregular Alpine ridgeline. The primary banner, especially the shear zone associated with the famous mistral wind of the lower Rhône valley in France, was expected to be well defined. Recent publications have addressed the primary mistral PVB that emanates from the south-western Alpine tip (Jiang and Smith 2003; Schär et al. 2003), as well as the secondary PVBs occuring north of the Alps (Grubisić 2001) and over the Adriatic Sea (Grubisić 2003).

This paper seeks to provide insight into the origin and structure of the secondary PVBs (PVB2s) forecast by the Canadian Mesoscale Compressible Community (MC2) model (Benoit et al. 2002) over the Po valley, northern Italy, on 8 November 1999 (IOP 15 of the MAP SOP). It also aims to provide experimental evidence of the existence of 


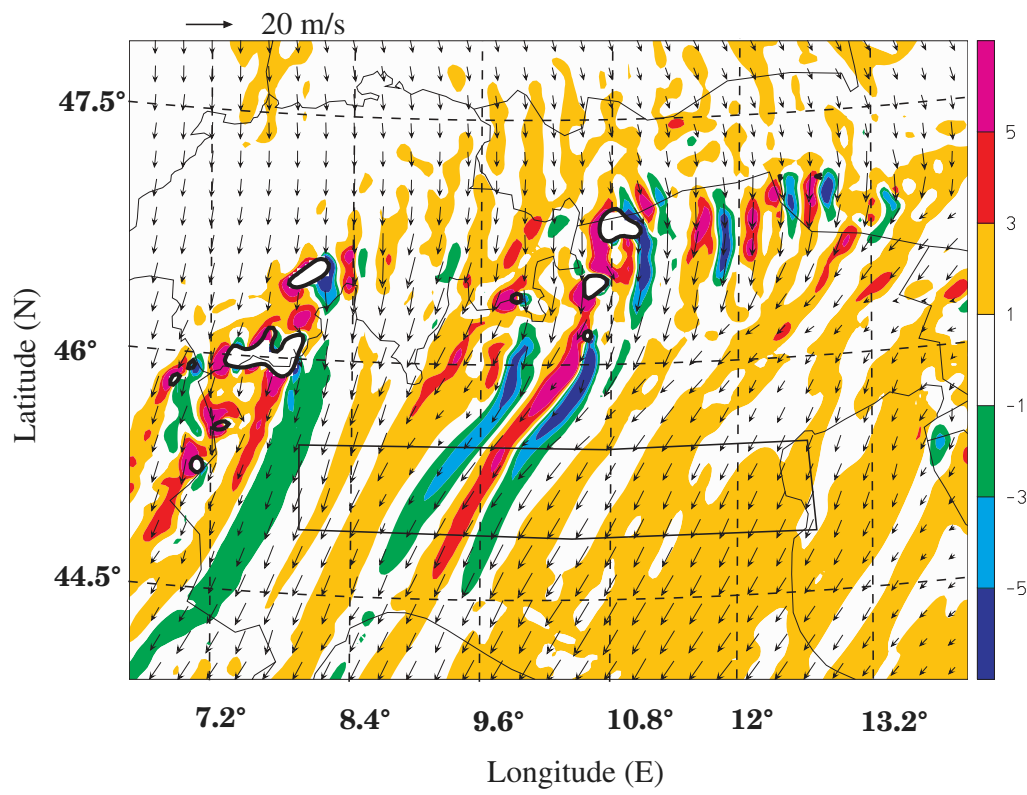

Figure 1. Potential vorticity field (PV units with $1 \mathrm{PVU}=10^{-6} \mathrm{~K} \mathrm{~m}^{2} \mathrm{~kg}^{-1} \mathrm{~s}^{-1}$ ) at $3 \mathrm{~km}$ resolution with overlain wind field (arrows) at $2700 \mathrm{~m}(720 \mathrm{hPa})$ forecast by the MC2 model at 1400 UTC on 8 November 1999. The black rectangle indicates the aircraft flight track.

such features using aircraft in situ and remote sensing data acquired during the MAP SOP. Figure 1 shows the PV field forecast at $720 \mathrm{hPa}$ by MC2, which was used to design the PVB2 mission. Numerous elongated PVBs advecting several hundreds of kilometres downstream of the Alps were forecast at the upper two levels. Besides the pairs of negative and positive PVB simulated downstream of the major gaps or valleys, PVB pairs were also simulated downstream of outstanding peaks, most likely as the result of flow splitting.

Three aircraft were available for the PVB2 mission performed on 8 November 1999. In situ measurements from three aircraft flying below the Alps crestline (at 2700,1500 and $600 \mathrm{~m}^{*}$ ) along two $350 \mathrm{~km}$ east-west oriented legs, designed to be approximately perpendicular to the northerly synoptic flow, were used to compute the PV experimentally assuming the lee-side flow to be two-dimensional (see section 3 for details on the observational strategy).

Furthermore, since there have been few non-idealized studies of PVB2 using highresolution numerical models, the 8 November 1999 event was simulated down to $2 \mathrm{~km}$ horizontal resolution using the mesoscale non-hydrostatic model Meso-NH in order to gain insight into the 3D structure of these features as well as their origin. This paper addresses several questions, including the following:

- What is the structure of the lee-side flow south of the Alps during a north föhn event? How does it relate to the mountain pass/peak distributions?

- What is the PV distribution associated with the lee-side flow?

- What are the processes responsible for the generation of PVBs?

- Can the existence of PVBs be diagnosed using aircraft in situ measurements?

* All heights mentioned are above mean sea level. 
- How well can a high-resolution mesoscale model such as Meso-NH simulate secondary PVBs?

In section 2, the synoptic environment leading to the forecast of PVB2 over the Po valley on 8 November 1999 is presented. The observing strategy and the platforms/instruments deployed over the Po valley, as well as the mesoscale models used in this study, are briefly presented in sections 3 and 4, respectively. In section 5, we analyse the 3D structure and thermodynamics of the flow over the Po valley using Meso$\mathrm{NH}$ simulations and aircraft measurements. In section 6 , we analyse the 3D structure of the PV field downstream of the Alps. We also discuss the expression used to compute the PV experimentally from aircraft measurements. Comparison with the PV simulated by Meso-NH is then discussed. In section 7, we summarize and conclude.

\section{SyNOPTIC SETTING ON 8 NOVEMBER 1999 OF IOP 15}

The time period from 6 to 9 November 1999 proved to be a very active one for the PVB project. On 6 November, an intense North Atlantic short-wave trough extending from the North Sea to France propagated south-eastward, followed by rapid cyclogenesis over the south-western Po valley. The northerly flow behind this trough resulted in the development of a mistral over the Ligurian Sea and north föhn flow over the Po valley. On 7 November, the centre of the surface cyclone was positioned over central Italy and the Tyrrhenian Sea and was slowly propagating to the south-east. On 8 November, the centre of the surface cyclone was positioned to the south-east of Italy, over the Mediterranean. The development of an anticyclone reaching from France to Germany and the Czech Republic resulted in a relatively strong north to south pressure gradient at lower levels across the entire Alpine chain. Conditions favourable to the mistral, north föhn, and bora started on 6 November and were maintained through to 9 November 1999. A primary PVB was forecast to be associated with the mistral, and PVB2s were forecast to be associated with the north föhn and bora.

Figure 2(a) shows the horizontal wind field at $3000 \mathrm{~m}$ simulated by Meso-NH at $1300 \mathrm{UTC}$ on the intermediate $8 \mathrm{~km}$ horizontal resolution domain. (Numerical simulations were performed using three nested domains, with horizontal resolutions 32, 8 and $2 \mathrm{~km}$ (see section 4).) At this altitude the deep north föhn flow is visible over the Alps. Weak flow splitting at the scale of the Alps is also seen upstream of the mountain range. Over the Po, the flow is northerly with a small easterly component. At this height the flow is almost orthogonal to the aircraft flight track. Further south (over central Italy), the eastern part of the flow is deflected to the west as the result of the presence of the Apennine range and the easterly flow associated with the cyclone positioned over the southern Adriatic.

At $1000 \mathrm{~m}$ (Fig. 2(b)), a well-defined bora flow is simulated by Meso-NH around the eastern flank of the Alps as the result of flow splitting occurring upstream of the Alpine range and the easterly flow associated with the cyclone centred over the southern Adriatic. At this altitude, the flow over the Po valley is much weaker than at $3000 \mathrm{~m}$, and the wind direction quite variable in the sheltered Po valley. Easterly winds as well as down-valley flows are visible in the vicinity of the aircraft flight track.

The ARPEGE* 1200 UTC analysis at $3000 \mathrm{~m}$ (not shown) indicates the presence of a north-west-south-east oriented front (warmer and drier side to the west) impinging on the western tip of the Alps. The northern part of the front was over France, while the southern part of the front was wrapped around the western tip of the Alps. In the process,

* Action de Recherche Petite Échelle et Grande Échelle. 


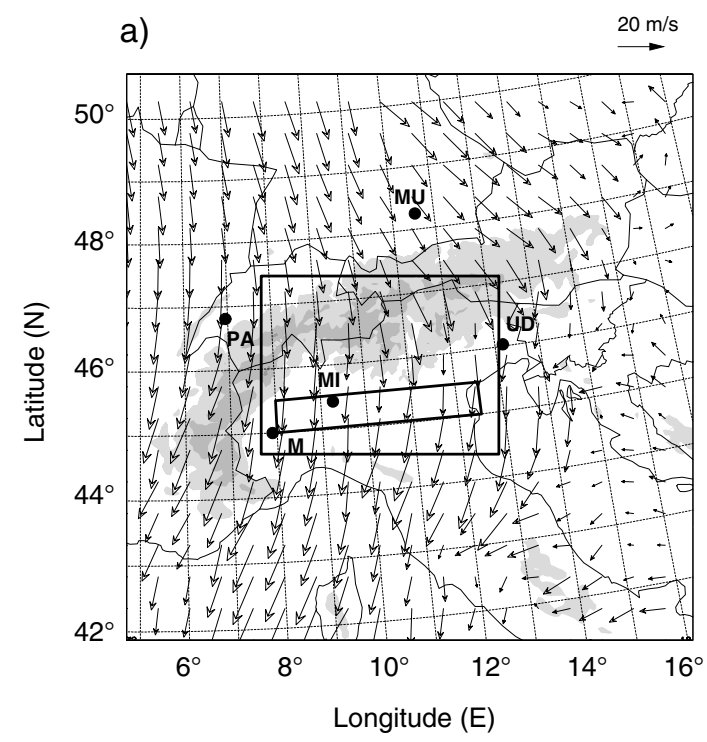

b) $20 \mathrm{~m} / \mathrm{s}$

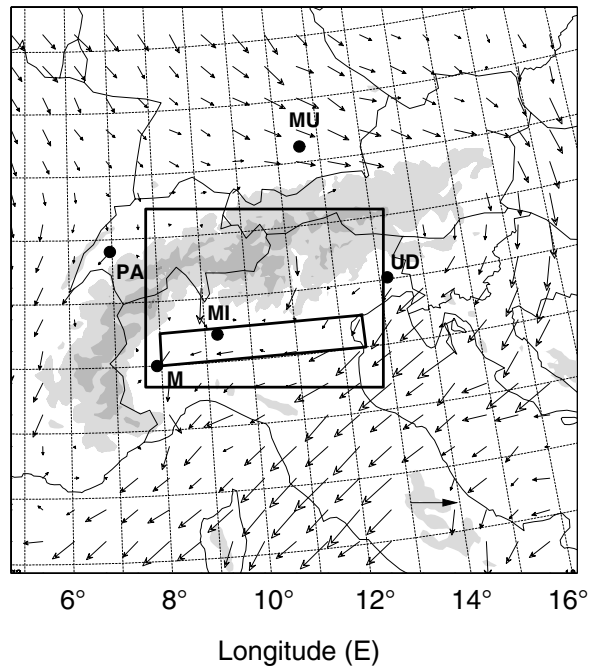

Figure 2. Horizontal wind field at (a) $3000 \mathrm{~m}$ and (b) $1000 \mathrm{~m}$ altitude, simulated by Meso-NH at $1300 \mathrm{UTC} 8$ November 1999 on the intermediate $8 \mathrm{~km}$ horizontal resolution domain. Terrain elevation is shaded (light grey represents $1000 \mathrm{~m}$, dark grey $2000 \mathrm{~m}$ ). Also superimposed are the position of the $2 \mathrm{~km}$ domain, the aircraft flight track, the locations of the synoptic sounding stations north (upstream: Payerne, PA and München, MU) and south (downstream: Milano, MI and Udine, UD) of the Alps and the location of the sounding performed by the Merlin (M) near Milano.

the front extended over most of central and southern Italy as well as the western part of the Po valley.

\section{OBSERVING STRATEGY}

PV is defined by thermal gradients and vorticity in all three dimensions. Although a recent study on the primary mistral banner (Schär et al. 2003) has shown that the dominant terms arise from the vertical component of the temperature gradient and the vorticity, contributions from horizontal components of the vorticity vector may not be completely disregarded. Hence, the experimental design for the PVB objective of MAP concentrated on measuring as many components of the vorticity field as possible, given the available resources. Emphasis was put on multi-aircraft operations in a coordinated, vertically stacked fashion along tracks oriented perpendicular to the flow.

Three aircraft were available for the PVB2 mission performed on 8 November 1999, namely the P-3, the Merlin IV, and the ARAT. In order to provide the information necessary to compute the PV experimentally (from in situ measurements), the three aircraft had to fly in close spatio-temporal coordination. The aircraft pattern was planned on the PV and wind fields forecast by MC2 at $720 \mathrm{hPa}$ (Fig. 1). At this level the flow structure was much less complicated and perturbed by the orography than at lower levels, which made it easier to design a fairly 'simple' flight pattern. (Long, straight, and level legs were needed to ease coordination and the experimental computation of the PV.) A box-shaped flight track with two east-west oriented legs approximately perpendicular to the flow forecast at $720 \mathrm{hPa}$ was chosen. The Merlin IV, the P-3 and the ARAT flew stacked legs at 600, 1500 and $2700 \mathrm{~m}(950,850$ and $720 \mathrm{hPa})$, respectively, between 1235 and 1500 UTC. In this paper, we shall focus on the in situ data acquired along leg PO (1238-1345 UTC) and leg NQ (1355-1450 UTC). The lengths of legs PO 
and NQ are approximately the same $\left(\approx 350 \mathrm{~km}\right.$, between $8^{\circ} \mathrm{E}$ and $\left.12.5^{\circ} \mathrm{E}\right)$. The two legs are separated by roughly $55 \mathrm{~km}\left(0.5^{\circ}\right.$ of latitude). The spacing of these two legs is not conducive to capturing fine-scale north-south gradients in the flow field. Rather, the purpose of these two legs was to observe the downstream evolution of the PVB2.

An overview of both the in situ and remote sensing instruments on board the ARAT and the Merlin is provided by Chalon et al. (1998). Detailed characteristics of the in situ sensors used to compute mean and turbulent thermodynamical and dynamical variables can be found in Lambert and Durand (1998). The sampling rates range from 4 to $256 \mathrm{~Hz}$ for the ARAT and from 1 to $25 \mathrm{~Hz}$ for the Merlin, depending of the type of measurement. The three components of the wind are computed from attack and slip angles obtained from pressure probes (Rosemount 858 and Rosemount 1221F for the ARAT and Merlin, respectively) as well as heading, roll, pitch and ground speed measurements performed with an Inertial Navigation System Sagem ULIS 45 I (both aircraft). The sampling rate of these variables (and hence the three components of the wind) is 64 and $25 \mathrm{~Hz}$ for the ARAT and Merlin, respectively. Static pressure is sampled by a Crouzet transducer $(16 \mathrm{~Hz})$ and by a Sextant ump40 probe $(25 \mathrm{~Hz})$ on the ARAT and Merlin, respectively. Air temperature (Rosemount 102E2AL) and dew point temperature (General Eastern 1011B) are sampled at 64 and $8 \mathrm{~Hz}$, respectively, on the ARAT and at $25 \mathrm{~Hz}$ on the Merlin. In the final stage of production, the data are averaged at $1 \mathrm{~Hz}$ and stored in ASCII files for scientific use.

The information on the NOAA P-3 instrumentation is described in detail by Jorgensen (1984). The navigation information (position and ground speed) was produced using a combination of GPS and INE information (Matejka and Lewis 1996). Static pressure (Garrett transducer), air temperature (Rosemount platinium resistance) and dew-point temperature (General Eastern cooled mirror) are sampled at $40 \mathrm{~Hz}$. The vertical component of wind is calculated using the algorithm documented in Jorgensen and LeMone (1989). The horizontal components of wind are computed from attack and slip angles obtained from a pressure probe (Rosemount transducer) as well as heading, roll and pitch measurements performed with an Northrop/Delco Inertial Navigation System at a sample rate of $40 \mathrm{~Hz}$. In the final stage of production, the data are averaged at $1 \mathrm{~Hz}$ and stored in ASCII files.

The resolutions and accuracies for the variables of interest to this study were compiled from publications and unrefereed sources for the three aircraft. The resolutions/accuracies are of the order of $0.1 / \pm 1 \mathrm{~m} \mathrm{~s}^{-1}$ for horizontal winds, $0.01 / \pm 0.5 \mathrm{~m} \mathrm{~s}^{-1}$ for vertical winds, $0.03 / \pm 0.3 \operatorname{degC}$ for air temperature and $0.03 / \pm 0.4 \operatorname{deg} C$ for dew point temperature. The resolution, accuracies and time responses of the instruments are adequate for a detailed analysis of the structure of the PVBs.

\section{Modelling STRATEGY}

In this paper, Meso-NH simulations are used to provide the 3D environment necessary for the interpretation of airborne measurements. To complete this objective, rigorous verifications of the Meso-NH simulations needed to be undertaken against available observations. These are presented in section 5 .

The Meso-NH model (Lafore et al. 1998) solves the non-hydrostatic, anelastic equation system. It allows for research in a wide range of topics, from large-eddy simulations (Cuxart et al. 2000) to the meso- $\alpha$ scale studies (Mallet et al. 1999). For this simulation, Meso-NH was used in the MASDEV4.1/BUG3 version and was driven by the operational Météo-France ARPEGE analyses available every 6 hours. Domains of 2 and $8 \mathrm{~km}$ resolution were nested within a $32 \mathrm{~km}$ resolution domain using 
two-way interfaces described in Stein et al. (2000). The positions of the 8 and $2 \mathrm{~km}$ resolution domains are shown in Fig. 2. A 12-hour simulation initialized at 0600 UTC on 8 November 1999 was completed for all three domains. The spin-up time for the simulation is 2 hours. The vertical grid was the same for all three simulations-60 levels using a stretched mesh with vertical grid spacings between 50 and $500 \mathrm{~m}$. To ensure a good description of the atmospheric boundary layer (ABL), 12 levels were taken below $1000 \mathrm{~m}$, with a grid spacing for the first 9 levels of less than $100 \mathrm{~m}$. The grid spacing above $6400 \mathrm{~m}$ was set to a constant of $500 \mathrm{~m}$. An absorbing layer was set above $15 \mathrm{~km}$, and the top of the domain was located at $21.4 \mathrm{~km}$. For all simulations, the turbulence scheme (Cuxart et al. 2000) was used in its unidimensional version. The convection and radiation schemes, as well as the parametrization of land-surface processes, are described in Bechtold et al. (2001), Morcrette (1991) and Noilhan and Planton (1989), respectively. The orography in Meso-NH is specified from the Global Land One-km Base Elevation database by averaging over each grid mesh and subsequent filtering. The amplitude of the filtered signal for each $n \Delta x$ wavelength is $\{\cos (2 \pi / n)+1\} / 2$. From this, it follows that the $2 \Delta x$ signal is removed, whereas $75 \%$ of the $6 \Delta x$ signal is retained. This is consistent with the suggestions made by Davies and Brown (2001) to remove orography at scales twice the model grid length, but use a selective filter to minimize the impact on scales larger than six times the model grid spacing.

In the following section, the mesoscale environment of the target area and the 3D structure of the flow over the Po valley are illustrated using model output at 1300 and 1400 UTC.

\section{3D DYNAMICS AND STRUCTURE OF THE FLOW OVER THE PO VALLEY FROM AIRBORNE OBSERVATIONS AND NUMERICAL SIMULATIONS}

In the following, the 3D flow over the Po valley was analysed using 2D horizontal and vertical cross-sections of thermodynamical variables produced by Meso-NH. The Meso-NH simulation was first validated using available measurements of horizontal wind, potential temperature and relative humidity $(\mathrm{RH})$. Observations included aircraft measurements over the Po valley and balloon soundings from synoptic stations upstream and downstream of the Alps (4 and 3 stations, respectively). We shall now present model comparisons against upstream soundings at Payerne and München-Oberschleissheim, downstream soundings at Milano and Udine, and the aircraft measurements on legs PO and NQ at all three levels (see Fig. 2). These basic comparisons gave us confidence that the simulation was well behaved on the 8 and $2 \mathrm{~km}$ resolution domains shown in Fig. 2. We feel the simulation can be used reliably to proceed with a model-based analysis of the thermodynamics and structure of the flow over the Po valley over the simulation domains.

The flow structure and dynamics at the aircraft flight levels were investigated using horizontal cross-sections of the wind field extracted from the simulation. Even though these cross-sections provided fairly convincing evidence of the links between the air masses sampled over the Po valley and the topographic features upstream in the central part of the Alps, we have conducted back-trajectory analyses because of the complex topography. At each level, on both legs, we have identified the jet-like structures and run the back-trajectory analysis package developed by Gheusi and Stein (2002). Finally, to complement and refine the trajectory analysis, we also have conducted tracer analyses (which will not be shown here, but briefly discussed).

The topographic features referred to in the text are shown in Fig. 3 and some of the significant ones in Table 1. 


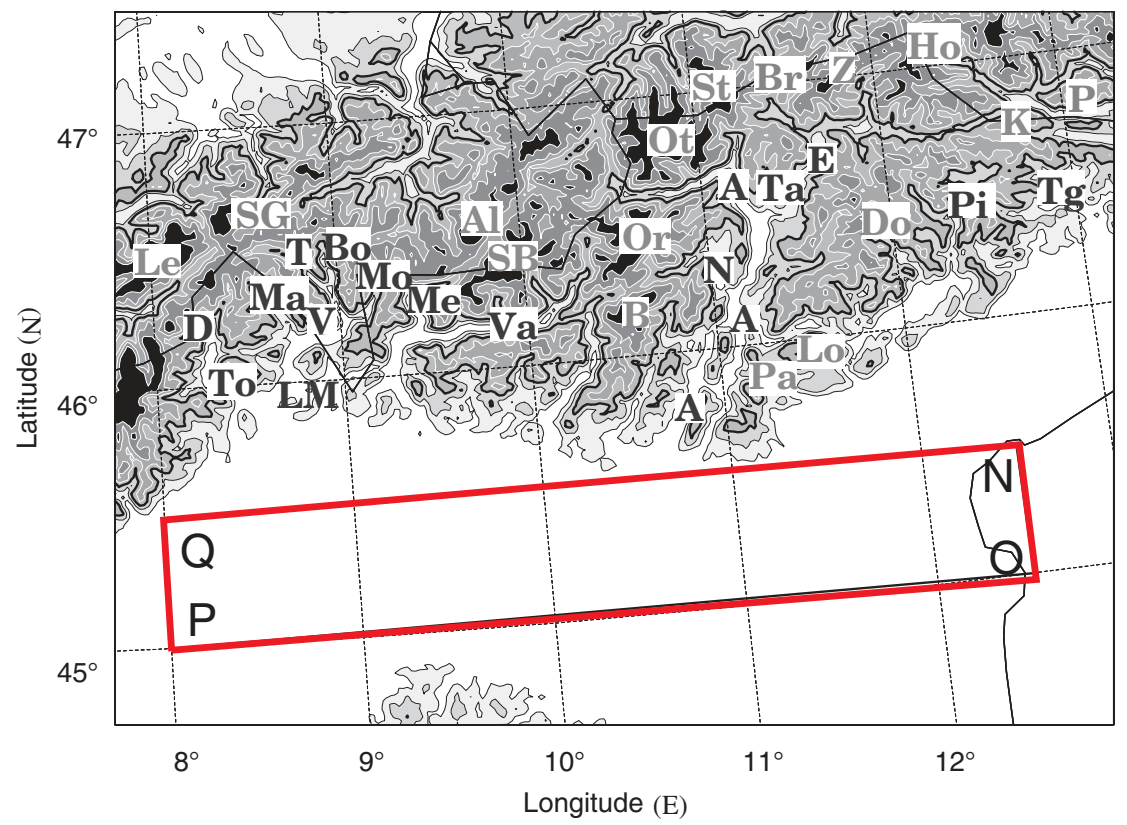

Figure 3. Aircraft trajectory over the Po valley on 8 November 1999 (thick red solid line PONQ) superimposed on terrain elevation. Contours of terrain elevation are plotted every $400 \mathrm{~m}$, starting at $600 \mathrm{~m}$. The thick black line corresponds to the $1400 \mathrm{~m}$ contour. Black-filled areas represent terrain above $2600 \mathrm{~m}$. The location of the geographic and orographic features referred to in this paper are also indicated (see also Table 1). The names of valleys or rivers are in blue: Diveria (D), Toce (To), Maggia (Ma), Ticino (T), Verzasca (V), Brenno (Bo), Moesa (Mo), Mera (Me), Valtelina (Va), Adige (A), Talfer (Ta), Eisack (E), Noce (N), Piave (Pi), and Tagliamento (Tg). The location of the Lago Maggiore (LM) is also indicated in blue. The names of the main passes are in green: St Gotthard (SG), Brenner (Br), and Plöcken (P). The names of mountains are in red: Alpi Lepontine (Le), Albula Alpen (Al), San Bernina (SB), Brenta (B), Ortes (Or), Ötztaler Alpen (Ot), Stubaier Alpen (St), Zillertaler Alpen (Z), Hohe Tauern (Ho), Karnische Alpen (K), Alpi Dolomitiche (Do), Monte Lozze (Lo), and Cima Palon (Pa).

Note that the political boundaries shown here are rough approximations of actual political boundaries.

TABLE 1. ALPINE PASSES (WEST TO EAST) RELEVANT TO THE ANALYSIS OF THE FLOW STRUCTURE AND DYNAMICS IN THE LEE OF THE ALPS ON 8 NOVEMBER 1999, AND THE VALLEYS CHANNELLING THE FLOW DOWNSTREAM OF EACH PASS

\begin{tabular}{llll}
\hline Massif & \multicolumn{1}{c}{ Pass (country) } & Location (N, E) & Downstream valleys \\
\hline Western Alps & Simplon (CH) & $46^{\circ} 15^{\prime}, 8^{\circ} 03^{\prime}$ & Diveria, Toce \\
& Nufenen (CH) & $46^{\circ} 29^{\prime}, 8^{\circ} 19^{\prime}$ & Toce, Maggia \\
& St Gotthard (CH) & $46^{\circ} 34^{\prime}, 8^{\circ} 31^{\prime}$ & Leventina, Verzasca \\
& Lukmanier (CH) & $46^{\circ} 34^{\prime}, 8^{\circ} 48^{\prime}$ & Brenno \\
& San Bernardino $(\mathrm{CH})$ & $46^{\circ} 30^{\prime}, 9^{\circ} 11^{\prime}$ & Moesa \\
& Splügen (CH) & $46^{\circ} 31^{\prime}, 9^{\circ} 21^{\prime}$ & Mera \\
Central Alps & Gampen (IT) & $46^{\circ} 33^{\prime}, 11^{\circ} 03^{\prime}$ & Noce \\
& Brenner (AU/IT) & $47^{\circ} 02^{\prime}, 11^{\circ} 32^{\prime}$ & Adige, Talfer, Eisack \\
Eastern Alps & Kreuzberg (IT) & $46^{\circ} 40^{\prime}, 12^{\circ} 28^{\prime}$ & Piave \\
& Plöcken (AU/IT) & $46^{\circ} 37^{\prime}, 12^{\circ} 58^{\prime}$ & Tagliamento \\
\hline
\end{tabular}

Countries: CH Switzerland, IT Italy, AU Austria.

Passes and valleys with the greatest influence on the lee-side flow are in bold.

Western Alps: Alpi Lepontine, Albula Alpen, and San Bernina.

Central Alps: Brenta, Ortles, Ötztaler Alpen, Stubaier Alpen and Zillertaler Alpen.

Eastern Alps: Hohe Tauern and Karnische Alpen.

See also Fig. 3. 

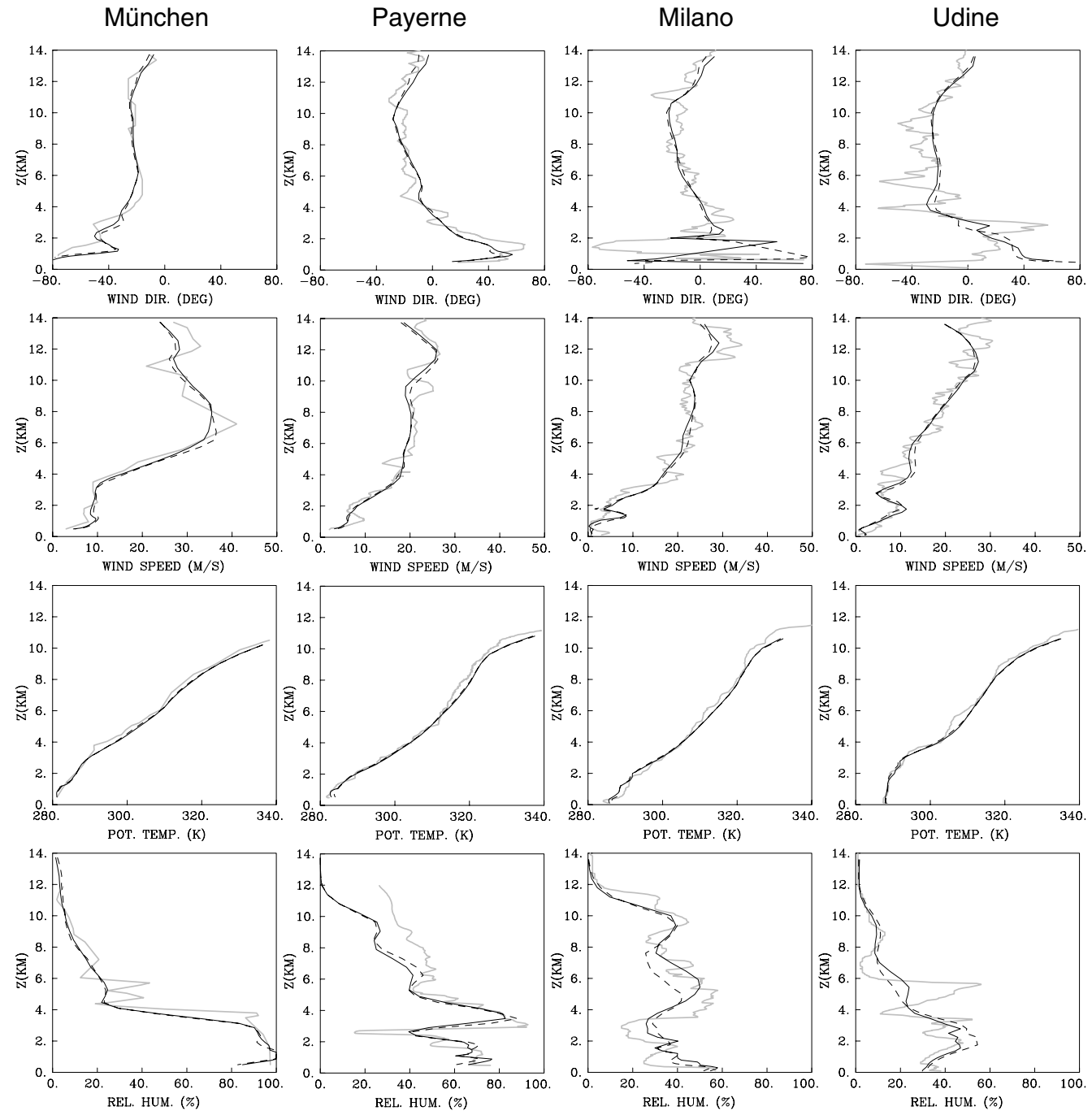

Figure 4. Comparison of vertical profiles of wind direction, wind speed, potential temperature and relative humidity (from top to bottom) on 8 November 1999, extracted from the model simulation at 1200 UTC (solid black line) and 1300 UTC (short dashes), and acquired from synoptic soundings launched at 1200 UTC (solid grey line) at Müchen-Oberschleissheim, Payerne, Milano and Udine (marked MU, PA, MI and UD in Fig. 2).

\section{(a) Atmospheric structure up- and downstream of the Alps}

To assess the quality of the simulated upstream conditions north of the Alps, vertical profiles of wind speed, wind direction, potential temperature and relative humidity have been extracted from the Meso-NH simulation ( $8 \mathrm{~km}$ resolution domain) at 1200 and 1300 UTC on 8 November 1999 at München-Oberschleissheim and Payerne (see Fig. 2) and compared with synoptic soundings launched at 1200 UTC. (Comparisons were also made with soundings launched at Stuttgart and Kuemmersbruck, but are not shown here.) The comparisons are shown in Fig. 4. For wind speed, wind direction and potential temperature, the overall agreement between the simulation and the observations is quite good up to $14 \mathrm{~km}$. The discrepancies can be explained by the fact that we are comparing point measurements (the soundings) with simulated variables horizontally averaged over 
the $(8 \mathrm{~km})$ mesh size. Furthermore, the profiles extracted from the simulation can also be considered instantaneous, which is not the case for the balloon soundings. Below $1 \mathrm{~km}$, the large-scale deflection pattern is well reproduced by the model; the flow is deflected to the east at München-Oberschleissheim and to the west at Payerne. At $3 \mathrm{~km}$, the near-northerly flow conditions at Payerne are well reproduced. Similarly, the slight easterly component of the flow simulated at München is consistent with the observations. Furthermore, the agreement between observed and simulated RHs below $6 \mathrm{~km}$ is quite exceptional.

Similar comparisons have been conducted to assess the quality of the downstream conditions south of the Alps. Comparisons for the selected sites (Milano and Udine, Fig. 2) are shown in Fig. 4. The overall agreement between the observations and the simulation is quite good for wind speed and potential temperature. For RH, the agreement at Milano is reasonable, but the enhanced humidity observed at Udine between 4 and $6 \mathrm{~km}$ is not simulated, although the rest of the simulated profile agrees with the observations. Below $2 \mathrm{~km}$, the wind direction at both stations is not well reproduced; measurements suggest westerly flow (most likely associated with downvalley winds), whereas the simulation suggests easterly winds associated with flow splitting at the scale of the Alps. However, in the lee of the Alps, the agreement between point measurements and simulated variables horizontally averaged over the mesh size is expected to be worse than upstream, due to the interaction of the upstream flow with the complex 3D structure of the Alps.

\section{(b) Observations and simulations on the northern leg}

Figure 5 shows four variables (wind speed, wind direction, potential temperature and relative humidity) measured by the ARAT $(2700 \mathrm{~m})$, the P-3 $(1500 \mathrm{~m})$ and the Merlin IV $(600 \mathrm{~m})$, along leg NQ (closer to the Alpine ridge) between 1350 and 1450 UTC on 8 November 1999.

Trajectories ending at 1300 UTC at the location of the jets observed on leg NQ (marked by 'J's in Fig. 5(a) and summarized in Table 2) at 2700, 1500 and $600 \mathrm{~m}$ are shown in Fig. 6(d) to (f), respectively.

(i) $2700 \mathrm{~m}$. At the upper level (Fig. 5(a)), three main jets were observed, which were also simulated by Meso-NH: the wider jet (centred at $9^{\circ} \mathrm{E}$ ) was associated with the $\mathrm{St}$ Gotthard Pass and the numerous other important passes in the Alpi Lepontine (Table 1), as suggested by the horizontal wind field at $2700 \mathrm{~m}$ simulated by Meso-NH at 1400 UTC (Fig. 6(a)) and the back-trajectory analyses (Fig. 6(d)) associated with the jet observed at $8.7^{\circ} \mathrm{E}$. The second jet (centred at $10^{\circ} \mathrm{E}$ ) was narrow and appeared to be associated with a gap between the San Bernina and Ortles mountains (Fig. 3 and Fig. 6(a)). This was confirmed by the trajectory analysis associated with the jet observed at $10.1^{\circ} \mathrm{E}$. Finally, Fig. 6(a) suggests that the jet centred at $11^{\circ} \mathrm{E}$ was associated with the merging of two jets, one downstream of the Brenner Pass $\left(47^{\circ} 02^{\prime} \mathrm{N}, 11^{\circ} 32^{\prime} \mathrm{E}\right)$ and a second downstream of the gap between the Ötztaler Alpen and the Stubaier Alpen. The jets in the lee of the gaps resulted from the lateral constriction experienced by the synoptic northerly flow upon reaching the passes. The back trajectories associated with the jets observed at $10.9^{\circ} \mathrm{E}$ and $11.2^{\circ} \mathrm{E}$, confirmed that they originated from the Ötztaler Alpen region and the Brenner Pass region, respectively.

Overall, the wind direction on the upper level was correctly reproduced (Fig. 5(b)). The observed/simulated winds were northerly. In both the observations and the simulation, marked trends in relative humidity $(\mathrm{RH})$ and potential temperature were evident 
(a)

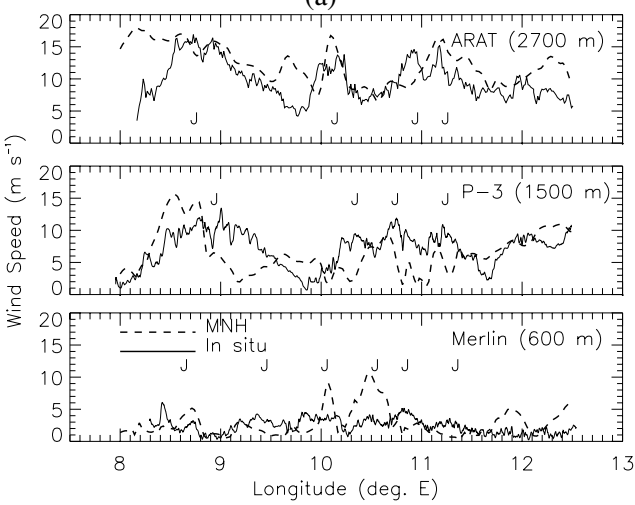

(c)

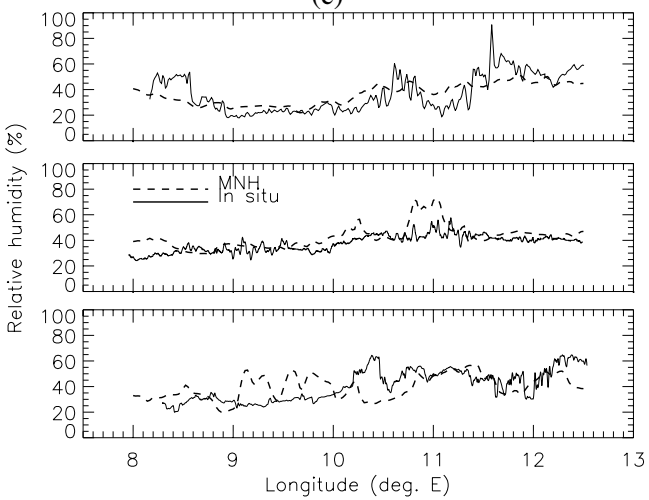

(b)

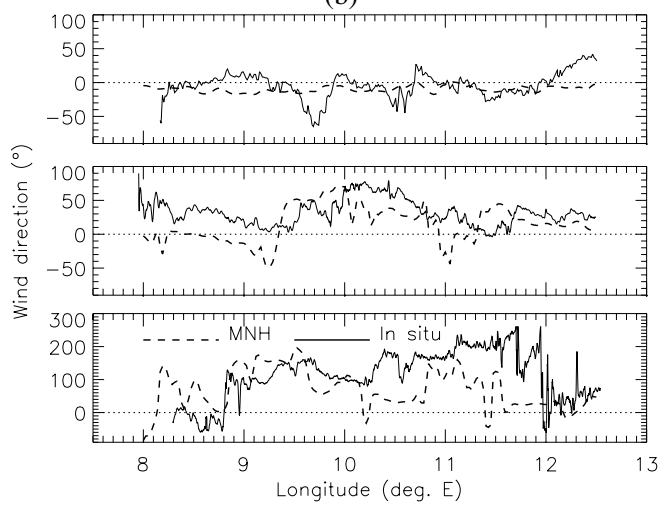

(d)

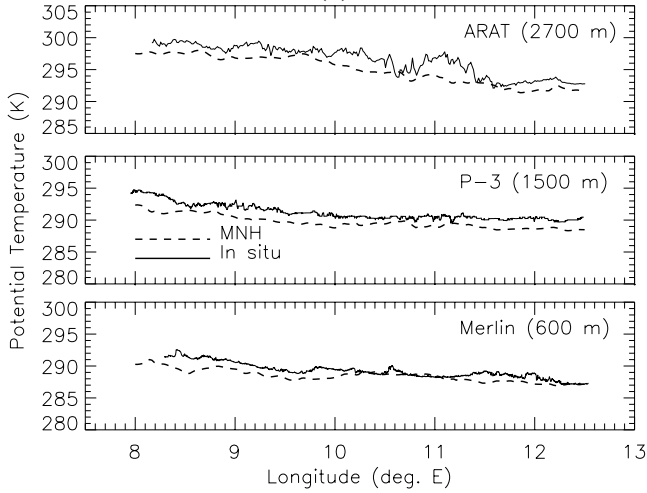

Figure 5. (a) Wind speed, (b) wind direction, (c) relative humidity, and (d) potential temperature measured by the ARAT (2700 m, upper panel), the P-3 (1500 m, middle panel) and the Merlin IV (600 m, lower panel) along leg NQ (closer to the Alpine ridge) between 1350 and 1450 UTC on 8 November 1999 (solid line). Superimposed are the variables extracted from the $2 \mathrm{~km}$ resolution Meso-NH simulations at 1400 UTC (dashed line). The 'J's in panel (a) mark the location of the jets listed in Table 2 . The dotted line in panel (b) marks the track-perpendicular wind direction.

TABLE 2. LONGITUDE $\left({ }^{\circ}\right.$ E) OF THE JETS OBSERVED ALONG LEGS PO AND NQ USED AS ENDPOINTS FOR THE BACK-TRAJECTORY ANALYSES CONDUCTED IN SECTION 5

\begin{tabular}{ccc}
\hline Height $(\mathrm{m})$ & Leg PO & Leg NQ \\
\hline 2700 & $8.3,9.6,10.1,10.7,11.7$ & $8.7,10.1,10.9,11.2$ \\
1500 & $8.2,10.0,11.6,12.3$ & $8.9,10.3,10.7,11.2,12.0$ \\
600 & $8.5,9.2,9.7,11.7$ & $8.6,9.4,10.0,10.5,10.8,11.3$ \\
\hline
\end{tabular}

along the aircraft track: RH increased and potential temperature decreased with increasing longitude (Fig. 5(c) and (d). These mesoscale trends were linked to the wrapping of the synoptic front around the western tip of the Alps (see section 2). In the process, warmer and drier air was brought into the western part of the Po valley. The modulations of RH and potential temperature superimposed on the mesoscale trends were not observed to be strongly correlated with the wind speed maxima associated with the jets (i.e. lower RH and higher potential temperature values were not evident within the jets) as shown by the correlation values shown in Table 3 . Even though the trends 
(a)

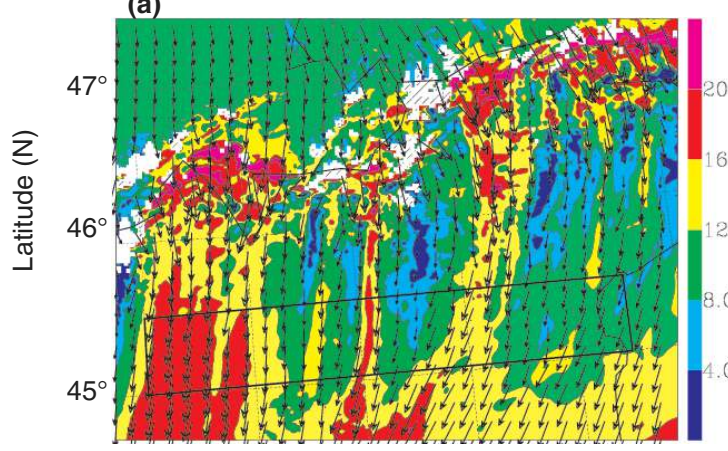

(b)

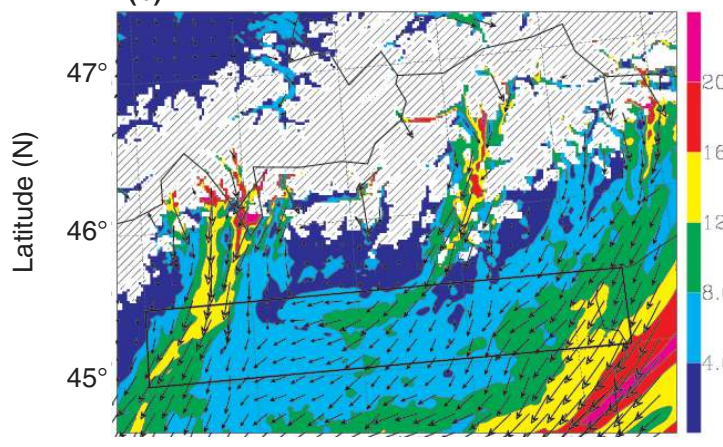

(c)

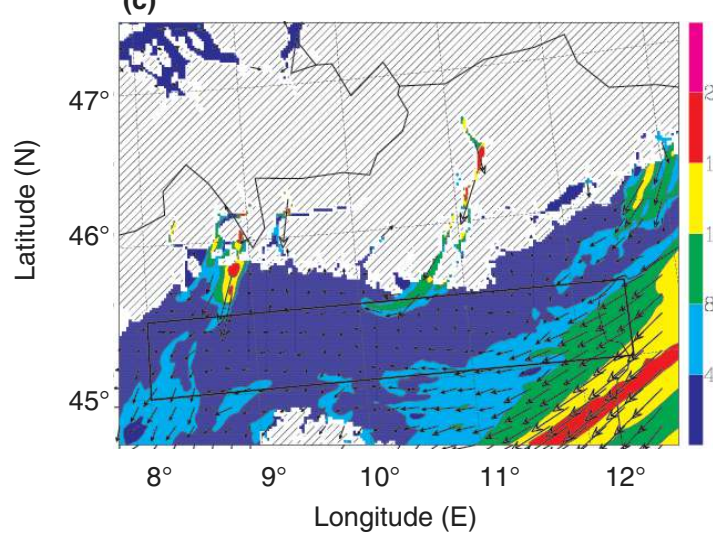

(d)

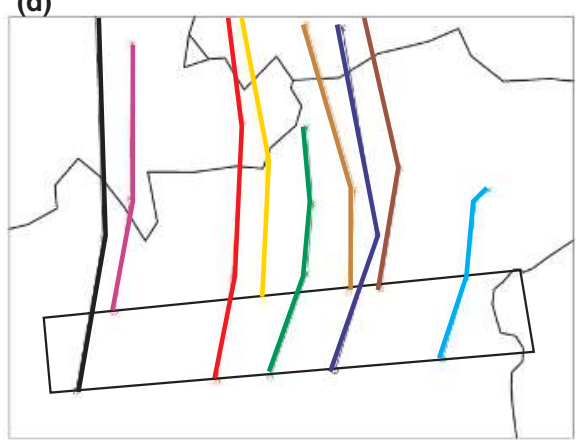

(e)

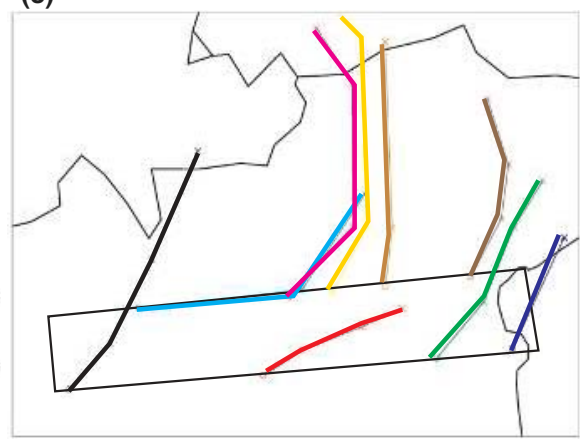

(f)

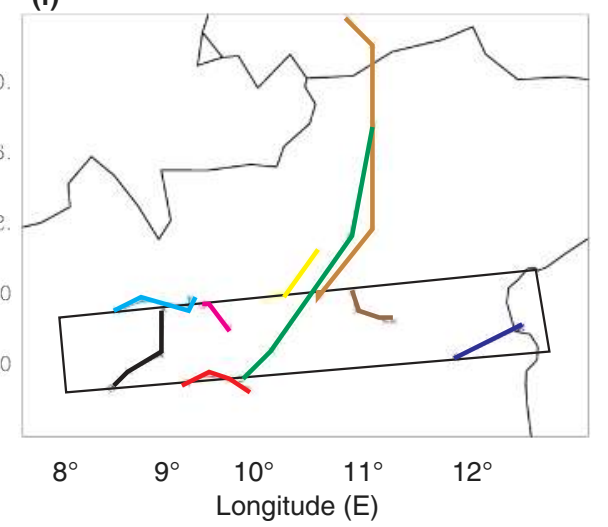

Figure 6. Left panels: 2-km resolution horizontal wind field at (a) $2700 \mathrm{~m}$, (b) $1500 \mathrm{~m}$, and (c) $600 \mathrm{~m}$ as obtained from Meso-NH at 1400 UTC on 8 November 1999. The hatched areas show the topography at each level. Wind speed $\left(\mathrm{m} \mathrm{s}^{-1}\right)$ and direction are given by the colour contours and arrows, respectively. Right panels: Back trajectories ending at 1300 UTC at the location of the jets observed on legs PO and NQ (summarized in Table 2) at (d) $2700 \mathrm{~m}$, (e) $1500 \mathrm{~m}$ and (f) $600 \mathrm{~m}$. Symbols mark the position along each trajectory at 1300, 1100, 0800 and 0600 UTC.

were correctly reproduced by Meso- $\mathrm{NH}$, the model has the tendency to underestimate potential temperature (cold bias of $1.6 \mathrm{~K}$ ). No systematic bias was found for RH.

(ii) $1500 \mathrm{~m}$. Two broad northerly jets (120-150 km wide) were observed at the mid level during this survey pattern (Fig. 5(a)). The horizontal wind field at $1500 \mathrm{~m}$, simulated by Meso-NH at 1400 UTC (Fig. 6b), shows that the jet to the west (composed of several smaller jets) occurred downstream of the Alpi Lepontine and appeared to 
TABLE 3. CORRELATION COEFFICIENTS BETWEEN WIND SPEED (FF), POTENTIAL TEMPERATURE (TH), AND RELATIVE HUMIDITY (RH) MEASURED in situ AT THE ARAT, P-3 AND MERLIN IV FLIGHT LEVELS

\begin{tabular}{llccc}
\hline & & FF & TH & RH \\
\hline ARAT & FF & - & 0.36 & -0.31 \\
$(2700 \mathrm{~m})$ & TH & 0.40 & - & -0.72 \\
& RH & -0.39 & -0.77 & - \\
P-3 & FF & - & -0.12 & 0.24 \\
$(1500 \mathrm{~m})$ & TH & 0.01 & - & -0.82 \\
& RH & -0.41 & -0.52 & - \\
Merlin & FF & - & 0.15 & 0.12 \\
$(600 \mathrm{~m})$ & TH & -0.37 & - & -0.80 \\
& RH & 0.12 & -0.89 & - \\
\hline
\end{tabular}

Values for leg PO are shown in roman, those for leg NQ in italic.

be channelled in several valleys upstream of the Lago Maggiore/Lago Lugano region (Lago Lugano is located slightly to the east of Lago Maggiore). The trajectory analysis revealed that the jet observed at $8.9^{\circ} \mathrm{E}$ originated from the Adige valley downstream of the Brenner Pass. However, recall that in this region the simulated wind direction was easterly whereas the sounding observations at Milano showed westerly winds (Section 5(a)). In this particular case, we do not trust the trajectory analysis, and believe that the jet observed at $8.9^{\circ} \mathrm{E}$ on leg NQ was indeed associated with the jet-like flow simulated downstream of the Lago Maggiore region. Since the trajectory analysis was not helpful, we have conducted tracer release analyses. From Fig. 6(b), six mountain passes were identified as playing a key role in channelling the flow and these are listed under 'Western Alps' in Table 1. In each of these passes, we have simulated the release of tracers from $1 \mathrm{~km}$ deep 'boxes' at three different altitudes (1000, 2000 and $3000 \mathrm{~m}$ ) at 0800 UTC, and analysed results at 1300 UTC. From this experiment, we are able to assess that the flows going through these six passes indeed contributed to the outstanding dynamical features (the jets essentially) of the flow over the Po valley as depicted in Fig. 6(b).

According to Fig. 6(b) and the tracer analyses (not shown), the strong flows channelled through the Maggia and Verzasca valleys on the one hand, and through the Ticino, Brenno and Moesa valleys on the other hand, merged to form two jets above Lago Maggiore and Lago Lugano, respectively, in a way that resembles the merging observed by Schär et al. (2003) using MC2 simulations. (See Fig. 3 for geographical locations.) These jets, in turn, merged to form the westernmost jet observed in Fig. 5(a). The western jet was simulated by Meso-NH at 1400 UTC to be narrower and stronger than observed (Fig. 5(a)). This may be an indication that the strength of the flow downstream of the Splügen Pass, in the Mera valley, was underestimated in the model.

The jet to the east occurred downstream of the Brenner Pass region and appeared to be channelled down the Talfer and then the Adige valley. In the Adige valley exit region $\left(10-11^{\circ} \mathrm{E}\right)$, the flow simulated along leg NQ exhibited a more complex structure than that observed. Instead of a broad jet, Meso-NH suggested the existence of two distinct jets slightly weaker than those observed. The westernmost of these two jets indeed corresponded to the flow channelled in the Adige valley, whereas the easternmost simulated jet appeared to be caused by the channelling between the Cima Palon and Monte Lozze. This origin was confirmed by the trajectory analysis associated with the jets observed at $10.3^{\circ} \mathrm{E}$ and $10.7^{\circ} \mathrm{E}$. Interestingly, the position of the two simulated 
jets coincided with observed increases in wind speed within the broad jet. Finally, the western edge of a third jet was sampled by the P-3 near $12^{\circ} \mathrm{E}$. This jet was associated with the flow downstream of passes in the Karnische Alpen (Table 1). Trajectory analysis suggested the jet observed at $12^{\circ}$ E originated from the Piave valley downstream of the Kreuzberg Pass.

Overall, the wind direction at the mid level was correctly reproduced (Fig. 5(b)). Due to flow splitting at the scale of the Alps, the flow curvature increased with decreasing altitude over the Po valley. At this level, this curvature is illustrated by the difference between the observed/modelled wind direction and the cross-track wind direction $\left(0^{\circ} \mathrm{N}\right.$ in this case) shown by the dotted line. Although not as marked, the RH and potential temperature trends observed at the upper level are also evident at the mid level (Fig. 5(c) and (d)). The agreement between observations and simulations was better at the mid level than above, but an overestimation of RH (underestimation of potential temperature) in the model was also evident at this level. A moist bias (5\% on average) and a cold bias ( $1.5 \mathrm{~K}$ on average) were associated with the model outputs at $1500 \mathrm{~m}$.

(iii) $600 \mathrm{~m}$. At the low level, the flow along the northern leg was observed to be light (less than $5 \mathrm{~m} \mathrm{~s}^{-1}$ on average), highly variable in direction and mostly south-easterly to southerly (Fig. 5(a) and (b)), possibly as a result of the deflection of the northerly synoptic flow along the eastern flank of the Alps, as suggested by Meso-NH (Fig. 6(c)). Meso-NH tended to overestimate the strength of the low-level jets downstream of the Adige valley $\left(10^{\circ} \mathrm{E}\right)$, producing northerly flow (instead of southerly as observed from Merlin IV measurements) downstream of the Adige exit region and downstream of the Plöcken Pass. A series of jetlets was identified to conduct the trajectory analyses. Only the jet observed at $10.5^{\circ} \mathrm{E}$ was clearly identified as originating from the Adige valley downstream of the Brenner Pass. According to the simulation, the other observed jets are related to local recirculations in the Po valley.

The observed RH and potential temperature at this level exhibited the same eastwest trend observed aloft. The modelled potential temperature exhibited a cold bias of $1 \mathrm{~K}$, but there was no systematic bias on $\mathrm{RH}$. The difference in $\mathrm{RH}$ and potential temperature between the 950 and $850 \mathrm{hPa}$ and between the 720 and $850 \mathrm{hPa}$ flight levels was approximately constant along leg NQ.

\section{(c) Observations and simulations on the southern leg}

In Fig. 7, we compare aircraft measurements of wind speed, wind direction, RH, and potential temperature on the northern (NQ) and southern (PO) legs at the three flight levels. RH and potential temperature at all levels were not observed to evolve significantly with distance from the Alpine range (Fig. 7(c) and (d)), whereas the wind speed and direction did evolve. At the lower level, the wind speed and direction measurements (Fig. 7(a) and (b)) evolved significantly east of $11^{\circ} \mathrm{E}$, due to the fact that the Merlin encountered the bora (the strong deflection imposed by the Alps at this level) on the eastern part of leg PO. This picture is consistent with the Meso-NH simulation (Fig. 6(c)). For the mid and upper levels, the wind direction did not evolve significantly downstream (Fig. 7(b)). The trajectory analyses suggest that:

at $2700 \mathrm{~m}$ :

- $\quad$ the jet observed at $8.3^{\circ} \mathrm{E}$ originated from the St Gotthard Pass area,

- the jet observed at $9.6^{\circ} \mathrm{E}$ originated from the gap between the San Bernina and the Ortles mountains,

- the jet observed at $10.1^{\circ} \mathrm{E}$ originated from over the Ortles mountains, 
(a)

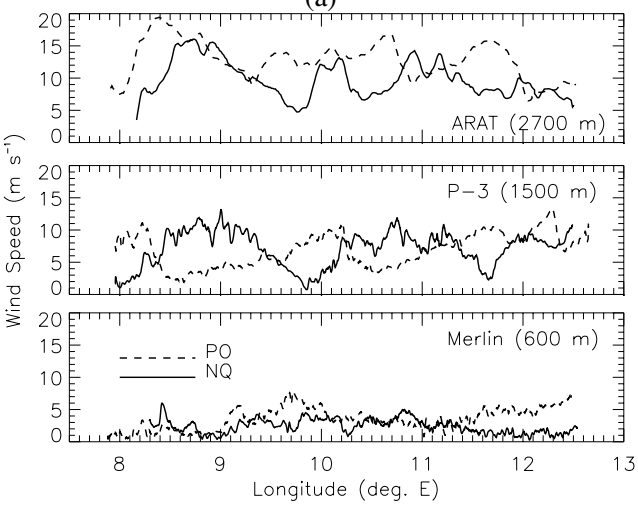

(c)

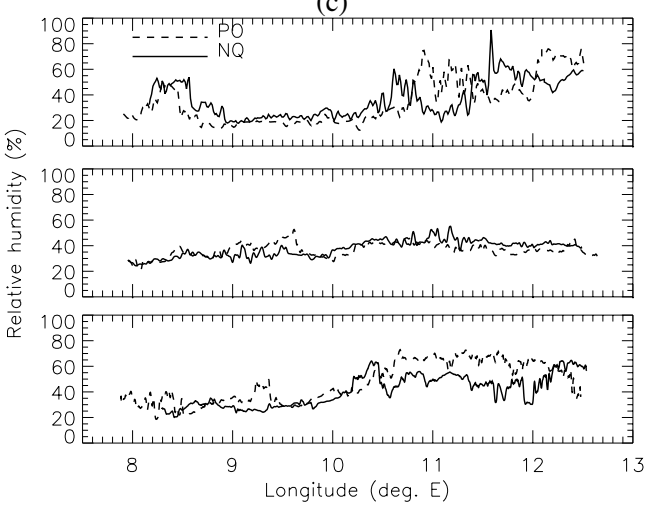

(b)

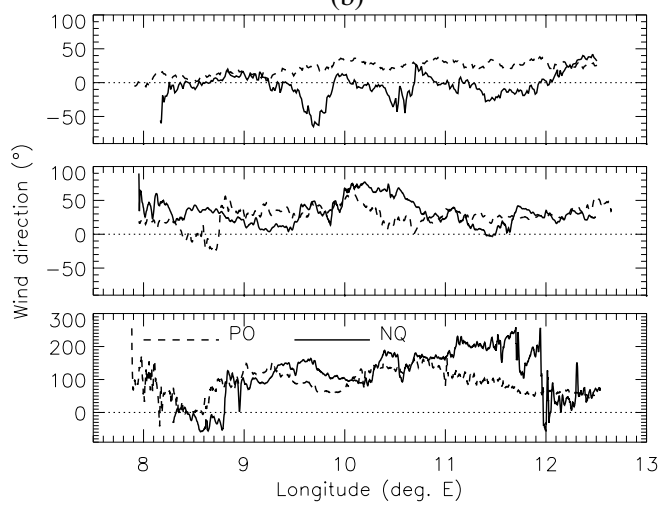

(d)

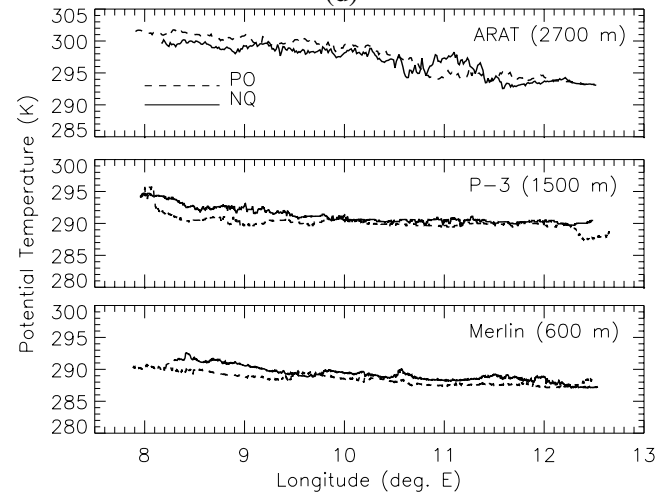

Figure 7. (a) Wind speed, (b) wind direction, (c) relative humidity, and (d) potential temperature measured by the ARAT (2700 m, upper panel), the P-3 (1500 m, middle panel) and the Merlin IV (600 m, lower panel) along leg NQ (solid line) between 1355 and 1450 UTC and leg PO (dashed line) between 1238 and 1345 UTC on 8 November 1999. The dotted line in panel (b) marks the track-perpendicular wind direction.

- $\quad$ the jet observed at $10.7^{\circ} \mathrm{E}$ originated from the Brenner Pass region (between the Stubaier Alpen and the Zillertaller Alpen),

- $\quad$ the jet observed at $11.7^{\circ} \mathrm{E}$ originated from over the Karnische Alpen.

at $1500 \mathrm{~m}$ :

- $\quad$ the jet observed at $8.2^{\circ} \mathrm{E}$ came from the Mera valley downstream of the Splügen Pass,

- $\quad$ the jet observed at $10^{\circ} \mathrm{E}$ appears to come from the Piave valley downstream of the Kreuzberg Pass, not from the Adige valley, because the Adige outflow is deflected to the west upon entering the Po valley and does not reach leg PO,

- the jet observed at $11.6^{\circ} \mathrm{E}$ originated from the Tagliamento valley downstream of the Plöcken Pass,

- $\quad$ the jet observed at $12.3^{\circ} \mathrm{E}$ was associated with the bora.

At the mid level, the maximum wind speed associated with the jets downstream of the St Gotthard Pass, the Brenner Pass, and the Plöcken Pass appeared to be shifted to the west (Fig. 7(a)), consistent with the picture emerging from the Meso-NH simulation (Fig. 6(b)). The width of the jet downstream of the Brenner Pass was also observed 
to be narrower on leg PO than on leg NQ. For the other jets this is difficult to assess, because only parts of the jets were sampled. At the upper level, a westward shift of the westernmost jet was also evident (Fig. 7(a)), but there still existed big structural differences between the two curves (especially concerning the two jets observed to the east on leg NQ).

The steadiness of the flow has been examined (using the model) to assess whether time variations could produce any of the differences between the observations along legs NQ and PO. Evidence of the steadiness of the flow upstream and downstream of the Alps has already been provided by profiles extracted from Meso-NH at 1200 and 1300 UTC (Fig. 4). For further insight into this issue, we also have compared the simulated variables of interest (wind speed and potential temperature) extracted on both legs and at all levels at 1300 and 1400 UTC (not shown). Only small-scale differences are visible between the fields extracted at 1300 and 1400 UTC, so that the flow can be considered steady from a thermodynamical point of view at the time of the observations.

\section{POTENTIAL VORTICITY: SIMULATIONS AND OBSERVATIONS}

In adiabatic, frictionless, and inviscid flow, PV is conserved. Hence, the PVBs that occur in the model analysis must be due to dissipative irreversible processes (Smith 1989b; Schär and Durran 1997). In principle, there are several possibilities. First, gravity-wave breaking above the mountain implies the presence of dissipative processes, and the violation of PV conservation (Schär, 1993). The PV generation processes will involve the (inviscid and adiabatic) tilting of baroclinically generated vorticity, and subsequent PV generation due to dissipative effects and heat transfer (Rotunno et al. 1999; Epifanio and Durran 2002). In a numerical model, the generation is due to parametrized turbulence, and/or artificial model diffusion that prevents a scale collapse. Second, PV generation may also occur in response to boundary layer processes. As the isentropic surfaces intersect a flank of the obstacle, the frictional force on an isentropic surface implies that its curl has a component perpendicular to the isentropes, thereby implying PV generation (Thorpe et al. 1993). Third, even with a free-slip lower boundary condition, PV generation can result from internal dissipative mechanisms. The process may be interpreted by using the generalized Bernoulli theorem (Schär and Durran 1997) or the boundary formulation of PV dynamics (Schneider et al. 2003). Fourth, at least in principle, diabatic heating associated with orographic precipitation may lead to the generation of PV anomalies. So far, however, there is no observational evidence that this process may lead to coherent PVBs.

The objective of this section is to provide some insight into the existence of PVBs in the atmosphere (using in situ measurements) and their origin (using Meso-NH simulations), in an area where they were forecast by MC2 during the MAP SOP. We start with the analysis of the 3D structure of the PV field downstream of the Alps based on Meso-NH simulations. We then investigate the origin of the PVB2s. Subsequently, we detail the method used and the assumptions made to derive the PV experimentally from aircraft measurements, as well as its limitations in the present case study. Finally, we compare the experimentally derived PV with the PV simulated by Meso-NH.

\section{(a) $3 D$ structure of the simulated $P V$}

In the Boussinessq approximation, $\mathrm{PV}$ is defined as

$$
q=\omega \cdot \nabla b
$$


where $\omega=(\xi, \eta, \zeta)$ is the vorticity, and $b$ is a buoyancy variable. In the model, the PV (also referred to as the 'full' PV) is computed as:

$$
q=\frac{1}{\rho} \frac{\partial \theta}{\partial x}\left(\frac{\partial w}{\partial y}-\frac{\partial v}{\partial z}\right)+\frac{1}{\rho} \frac{\partial \theta}{\partial y}\left(\frac{\partial u}{\partial z}-\frac{\partial w}{\partial x}\right)+\frac{1}{\rho} \frac{\partial \theta}{\partial z}\left(\frac{\partial v}{\partial x}-\frac{\partial u}{\partial y}+f\right),
$$

where $u, v$ and $w$ are the three components of the wind to directions $x$ (east), $y$ (north) and $z$ (zenith), respectively, $\theta$ is potential temperature, $f$ is the Coriolis parameter, and $\rho$ is the density of moist air.

Figure 8 shows the horizontal structure of the PV field simulated by Meso-NH at the flight levels of the three aircraft. At $2700 \mathrm{~m}$, the PV field consisted of a dense network of elongated PVBs advecting several hundred kilometres downstream of the Alpine crest line. Besides the pairs of negative and positive PVB simulated downstream of the major gaps (i.e. coinciding with lee-side jets), numerous PVB pairs were also simulated downstream of outstanding peaks such as the San Bernina, Ortles, and Hohe Tauern mountains. At $1500 \mathrm{~m}$, the PVBs were simulated to emanate from the numerous valleys in the Alpi Lepontine. The PVBs associated with the two jets above Lago Maggiore and Lago Lugano were advected over longer distances than those emanating from valleys to the east of Lago Lugano (Fig. 8(b)). No well-defined PVBs were simulated downstream of the Adige valley exit region. Several short PVBs were simulated east of the Adige valley, along the flank of the Alpine range, the best defined PVB pair being simulated downstream of the Tagliamento. At $600 \mathrm{~m}$, no well-defined banners were simulated in connection with the weak jets seen in the Lago Maggiore and Adige exit region (Fig. 8(a)). Overall, it is also hard to see any consistent relation between the structure of the PV field and the jet/wake structure at the lowest level.

The 2D vertical structure of the potential temperature and PV field simulated with Meso-NH along leg NQ is shown in Fig. 9(a). Three regions of distinct stratification are evident: (i) a strongly stratified layer for altitudes where $\theta>292 \mathrm{~K}$, (ii) the ABL whose depth was approximately constant and equal to $1.5 \mathrm{~km}$ west of $10.5^{\circ} \mathrm{E}$ and decreased with increasing longitude to $1 \mathrm{~km}$ east of $10.5^{\circ} \mathrm{E}$, and (iii) a 'buffer' layer between the top of the ABL and the bottom of the strongly stratified layer. Note that the depth of the 'buffer' layer increased with longitude from a few hundred metres (western part of the leg) to almost $2 \mathrm{~km}$ (eastern part of the leg). Concerning Meso-NH, PVBs were essentially simulated above the ABL, in the stratified part of the flow. The region downstream of the Ortles was the most active in terms of the number of PVBs and PVB strength. In many locations, PVBs appeared to penetrate into the buffer layer. However, none of these were simulated to reach the surface, suggesting the ABL was decoupled from the upper-level flow.

\section{(b) Origin of secondary PV banners simulated over the Po valley}

To obtain physical insight into PVB generation processes, we have analysed the latitudinal structure of selected PVBs seen in the Meso-NH simulation. The PV field was analysed along 6 vertical cross-sections. Similar conclusions were drawn from each cross-section, but we will discuss here only the results obtained on the westernmost cross-section, shown in Fig. 9(b), and shown as a thick north-south line in Fig. 8(a).

The PVB2 production mechanisms have been investigated on the basis of turbulent kinetic energy (TKE), potential temperature and PV fields. We have considered the two main PV production mechanisms, namely wave breaking and flow splitting. PV production linked to wave breaking is expected in regions where TKE is associated with nearly vertical isentropes. In this case, production regions are located above the lowest 

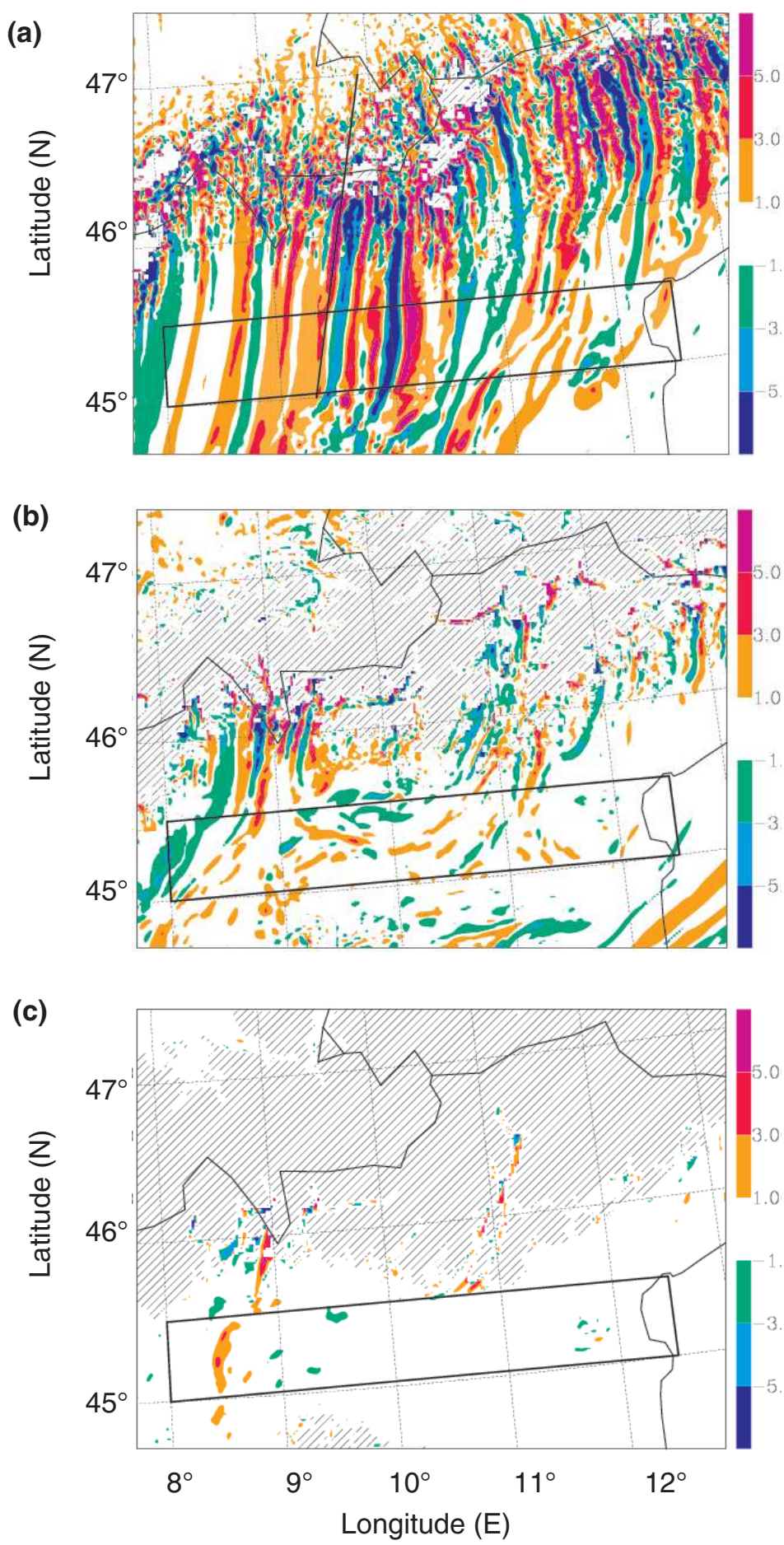

Figure 8. Potential vorticity (PV) at $2 \mathrm{~km}$ resolution at (a) $2700 \mathrm{~m}$, (b) $1500 \mathrm{~m}$ and (c) $600 \mathrm{~m}$, as obtained from Meso-NH at 1400 UTC on 8 November 1999. The hatched areas show the topography at each level. The PV fields are displayed in colour-coded PV units $\left(1 \mathrm{PVU}=10^{-6} \mathrm{~K} \mathrm{~m}^{2} \mathrm{~kg}^{-1} \mathrm{~s}^{-1}\right)$. The aircraft flight pattern is indicated by the black rectangle. The north-south solid line in (a) indicates the position of the $2 \mathrm{D}$ cross-section shown in Fig. 9(b). 
(a)

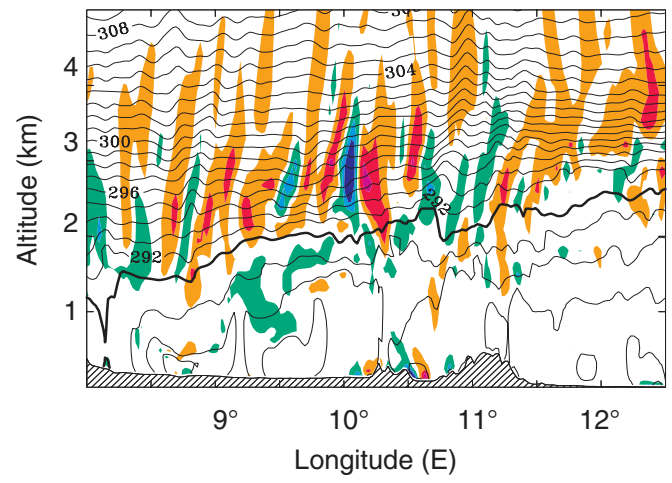

(b)

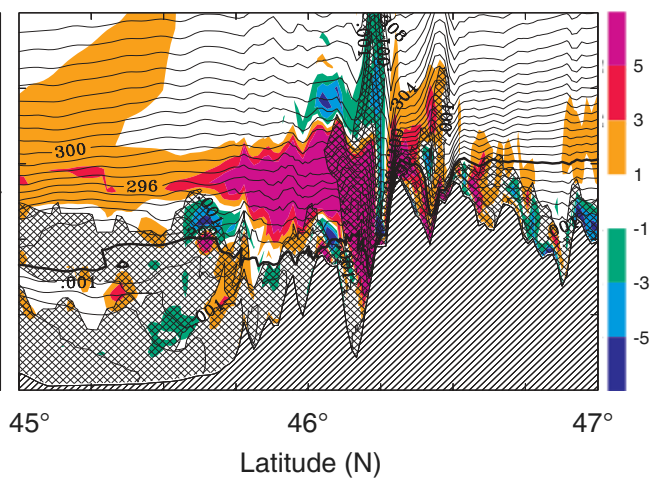

Figure 9. (a) Potential vorticity (colour coded PV units, $1 \mathrm{PVU}=10^{-6} \mathrm{~K} \mathrm{~m}^{2} \mathrm{~kg}^{-1} \mathrm{~s}^{-1}$ ) and isentropes (black contours) simulated by Meso-NH at 1400 UTC on 8 November 1999, along leg NQ. (b) Vertical structure of the PV field (PVU, colour coded) and isentropes (black contours) simulated by Meso-NH at 1400 UTC along the north-south cross-section shown in Fig. 8(a). Turbulent kinetic energy (more than $0.001 \mathrm{~m}^{2} \mathrm{~s}^{-2}$ ) is superimposed (cross-hatching above terrain), with the $291 \mathrm{~K}$ isentrope shown by a thick black contour.

isentrope passing over the topography. PV production by flow splitting is expected in regions where TKE is located below the lowest isentrope passing over the topography (i.e. where isentropes intersect the orography). Close inspection of the 6 cross-sections suggests that elongated PVB2 seen in the simulations are essentially generated through wave breaking mechanisms over the Alps (even though production by flow splitting cannot be completely discarded). In the particular case of the westernmost cross-section (Fig. 9(a)), the lowest isentrope passing over the topography is $\theta=291 \mathrm{~K}$. The PVB2 production region is located above $\theta=291 \mathrm{~K}$, downstream of the San Bernina on the northern slopes of the Valtelina. (TKE appears as the shaded area above the terrain in Fig. 9.) Further to the north, another PV production region is seen downstream of the Albula Alpen. However, the PV values associated with the latter topographic feature are much smaller than those associated with the former. Below $\theta=291 \mathrm{~K}, \mathrm{PV}$ is also seen to be produced via flow splitting mechanisms within the Valtelina and numerous valleys to the north. However, these production regions appear to be disconnected from the elongated PVB2 simulated over the Po valley.

Over the Po valley TKE is generated by buoyancy in the ABL, while the elevated layer of enhanced TKE located just below the PVB2 is associated with the wind shear in the wake of the Alps. Sporadic PV features rather than PVB2 are associated with the TKE below $2 \mathrm{~km}$.

In conclusion, simulations suggest that low-level gravity-wave breaking was the main mechanism responsible for the formation of the elongated PVB2 modelled over the Po valley.

\section{(c) Experimentally derived PV: method and limitations}

In this section, we use in situ aircraft data to further investigate the structure of the PVB2 over the Po valley. The distribution of the PV along the legs PO and NQ is computed from the aircraft in situ data assuming the lee-side flow to be two-dimensional and perpendicular to the legs flown by the aircraft (i.e. $\partial / \partial y=0$ ). Our goal is to compare experimentally derived and simulated PV. Due to the design of the experiment (see discussion in section 5), we anticipate three major sources of errors likely to complicate the model/data comparison: 
- The flow curvature below the Alps crestline. Due to flow-splitting at the scale of the Alps, the flow in the wake south of the Alps is not $2 \mathrm{D}$ at the lower two aircraft levels (unlike the flow at the ARAT level). Hence, all components of the PV are probably not captured by the experimental design.

- Time variations could produce some of the differences between the observations and the simulation along both legs, since data were acquired over a period of one hour whereas simulation outputs are instantaneous. Evidence of the steadiness of the flow upstream and downstream of the Alps has already been discussed on the basis of the thermodynamical variables. This needs to be verified for PV.

- Numerical issues. When computing horizontal and vertical gradients of geophysical variables from in situ measurements, we have used a finite-difference approach. Due to the high number of samples acquired along each leg, this method is well suited for the calculation of terms involving $\partial / \partial x$. On the other hand, given that only three levels were available to estimate vertical gradients, the method might not be suited to compute terms involving $\partial / \partial z$.

The first two points are discussed below and the third point is discussed in the appendix.

(i) Method. In the 2D flow assumption, the reduced form of the PV yields

$$
q=\frac{1}{\rho} \frac{\partial \theta}{\partial z} \frac{\partial v}{\partial x}-\frac{1}{\rho} \frac{\partial \theta}{\partial x} \frac{\partial v}{\partial z}
$$

where $q$ here is the 'simplified' PV, and $\rho$ is determined from in situ measurements as

$$
\rho=\frac{p}{R T_{\mathrm{v}}}
$$

where $p$ is the pressure, $R$ is the perfect gas constant for dry air $\left(=287 \mathrm{~J} \mathrm{~K}^{-1} \mathrm{~kg}^{-1}\right)$, and $T_{\mathrm{v}}$ is the virtual temperature.

Longitudinal series of $u, v, \theta, p$, and $T_{\mathrm{v}}$ for both legs and at all three levels were interpolated (linearly) onto 2800 regularly spaced grid points between $8.2^{\circ} \mathrm{E}$ and $12.2^{\circ} \mathrm{E}$, yielding a horizontal resolution of $107 \mathrm{~m}\left(\approx 0.00143^{\circ}\right.$ longitude $)$. The non-interpolated data consisted of 3721 and 2821 irregularly spaced data points on leg PO and NQ, respectively. Prior to the computation of the differentiated quantities, the flight level data have been smoothed using a 110-point window $(\approx 12 \mathrm{~km})$. The size of the window was chosen such that observed PV fluctuations could be consistently compared with modelderived PV fluctuations. It should be recalled that in the simulation over the smallest domain ( $2 \mathrm{~km}$ resolution), any fluctuation with a period less than $6 \Delta x$ is not realistic.

(ii) Flow curvature. Since Eq. (3) is used to compute PV experimentally at all flight levels, we need to assess whether the simplified form of the PV (SPV) given by Eq. (3) is a good approximation of the 'full' PV given by Eq. (2) despite the fact that the flow was not necessarily 2D and perpendicular to the track below the Alps crestline. The validity of Eq. (3) has been tested using Meso-NH model outputs. SPV along legs PO and NQ has been computed with Eq. (3) based on $v, \theta$ and $\rho$ fields extracted from Meso-NH simulations at the three flight levels. Figure 10 shows that at the ARAT flight level, the difference between the 'full' PV (shaded) and SPV (solid line) essentially lies in the amplitude of the fluctuations. At the ARAT flight level, Meso-NH simulations also showed that the second term on the right-hand side of Eq. (3) was negligible (not shown), which means that the phase (position) of the PVB2 along the leg was controlled by the term $\partial v / \partial x$, while the amplitude was controlled by the term $\partial \theta / \partial z$. At this level, the difference in amplitude between the two approaches could be due to the fact that, 
(a)

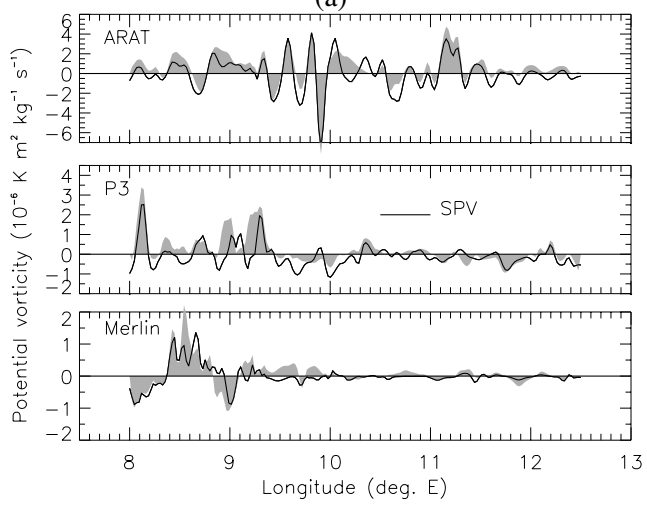

(b)

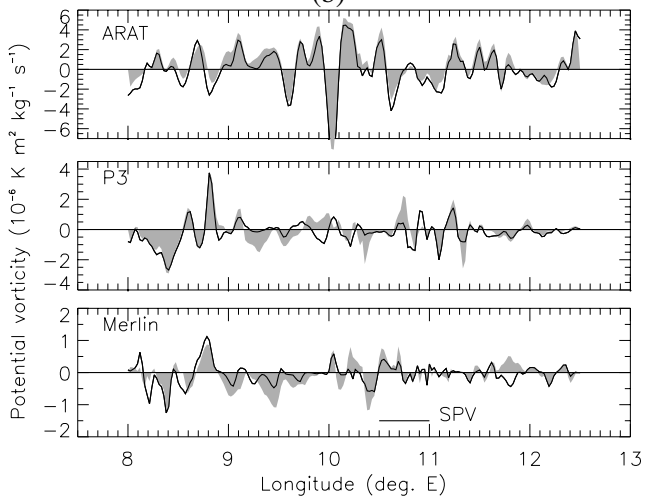

Figure 10. Potential vorticity computed by Meso-NH (shaded) and computed from the simplified equation (3) using Meso-NH simulations (solid line) along (a) leg PO and (b) leg NQ at the ARAT (2700 m, upper panel), the P-3 (1500 m, intermediate panel) and the Merlin IV (600 m, lower panel) flight levels at 1400 UTC on 8 November 1999.

using the finite-difference approach (see appendix), the term $\partial \theta / \partial z$ computed with data extracted at two flight levels is not a good approximation to that defined locally in the model, due to the high vertical resolution of the model.

At the two lower flight levels, SPV captures the larger, more well-defined PVB2s better than the small variations seen in the simulated PV field. The comparison was not as good as at the ARAT level since (i) the SPV did not necessarily reproduce all of the PV features, (ii) some SPV features were displaced along the leg with respect to their corresponding PV feature and (iii) in some places (e.g. leg NQ at $9^{\circ} \mathrm{E}$ ) SPV is negative whereas positive $\mathrm{PV}$ is produced in the simulation. Also at these levels, the two terms in Eq. (3) were found to be equally important for PV. At the P-3 and Merlin levels, the difference in amplitude between PV and SPV is likely to be due to terms not accounted for in Eq. (3) (i.e. the terms neglected when assuming the flow to be two-dimensional and perpendicular to the flight legs), and also to inaccuracies in the vertical gradient computations using the finite-difference approach.

This analysis suggests that Eq. (3) can be used with confidence to derive PV fluctuations experimentally at the ARAT flight level. At the P-3 and Merlin levels, even though the distribution of the flow definitely violates the assumption that the flow is $2 \mathrm{D}$ and perpendicular to the flight path, it appears that the east-west variations dominate the variations in the flow. (In other words, $\partial u / \partial x$ may be significant at low levels, but $\partial u / \partial y$ is still relatively small). Hence, it seems that the low-level curvature occurs on scales larger than those of interest. As a result, experimentally derived SPV could be compared directly to the simulated PV. Nevertheless, in the following we shall compare experimentally derived SPV with simulated SPV for consistency.

(iii) Time variations. For further insight into this issue, we have compared the simulated PV extracted over both legs and at all levels at 1300 and 1400 UTC (Fig. 11). The flow was nearly steady from a thermodynamical point of view at the time of the observations, and the structure of the PV field on leg NQ appears to be quite steady. This is not the case on leg PO, where structural differences exist in the PV field between 1300 and 1400 UTC. Hence, it is likely that time variations will induce discrepancies in the comparison between observations over a period of nearly one hour and instantaneous simulations. 
(a)

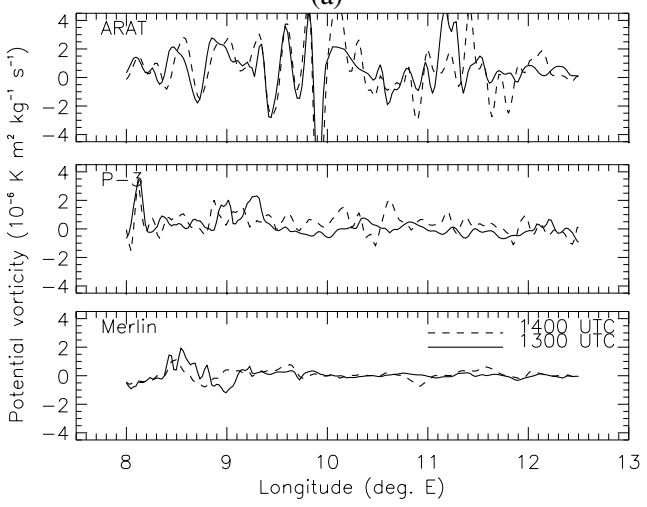

(b)

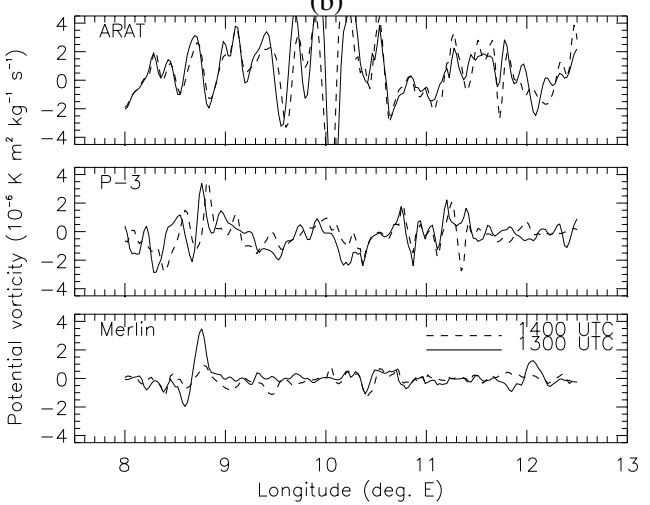

Figure 11. As Fig. 10, but simulated by Meso-NH on the $2 \mathrm{~km}$ resolution domain at 1300 UTC (solid line) and 1400 UTC (dashed line) on 8 November 1999.

(a)

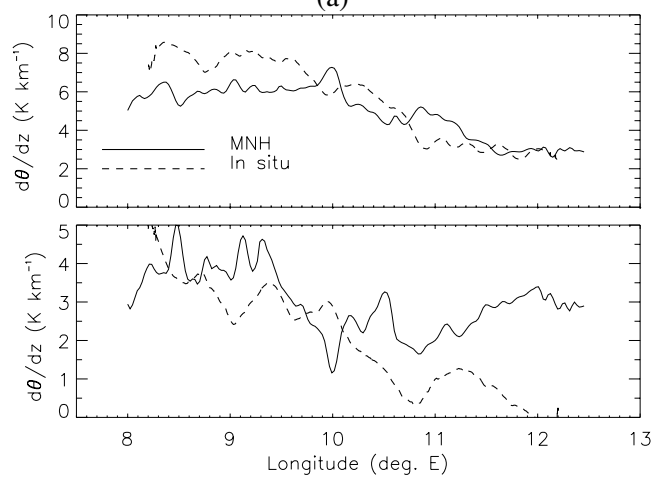

(b)

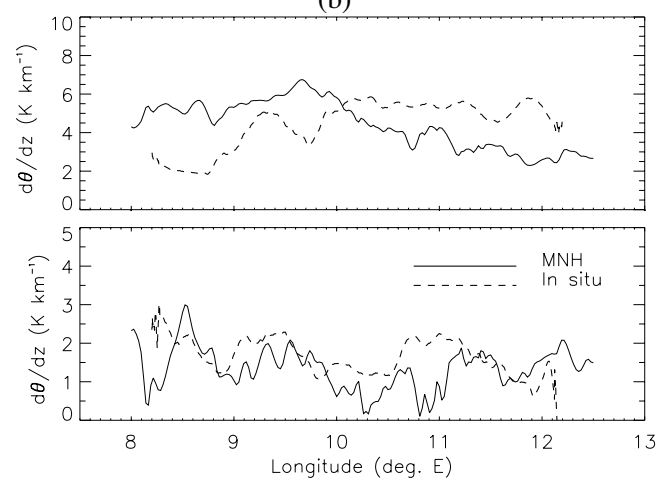

Figure 12. Vertical potential temperature gradients derived from in situ measurements (dashed line), and from Meso-NH (MNH; solid line), using the finite-difference approach, along (a) leg PO and (b) leg NQ. The gradients in the upper (lower) panels are computed from measurements made at the upper (lower) two flight levels.

\section{(d) Comparison between experimentally derived SPV fluctuations and simulations}

In this section, we first compare the experimentally derived vertical component of vorticity and vertical potential temperature gradient with those simulated by Meso- $\mathrm{NH}$, in order to help isolate potential sources of discrepancy between observed and simulated $\mathrm{PV}$. The comparison of experimentally derived PV fluctuations with simulations is then discussed.

A comparison of the vertical potential temperature gradients derived from in situ measurements, and the Meso-NH simulations (using the finite-difference approach, as for measurements) is shown in Fig. 12. The comparison for the vertical component of the vorticity (reduced to $\partial v / \partial x$ for a reliable estimate of $\partial u / \partial y$ could not be obtained from the measurements) is shown in Fig. 13 for in situ measurements and the Meso$\mathrm{NH}$ simulation. In Fig. 12, discrepancies between observations and the simulation of the vertical potential temperature gradient are evident on both legs and at both levels, except on leg NQ at the lower level where good agreement was found. Hence, noticeable differences in PV amplitude are to be expected between experimentally derived and model-derived PVB2s at all levels. Figure 13 shows that, even though the amplitudes 
(a)

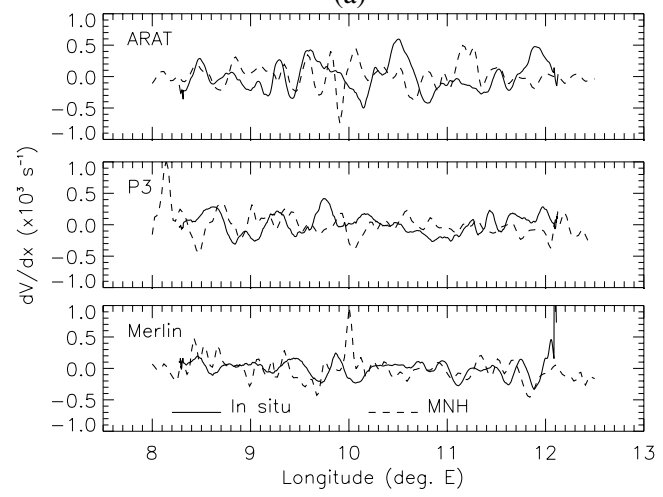

(b)

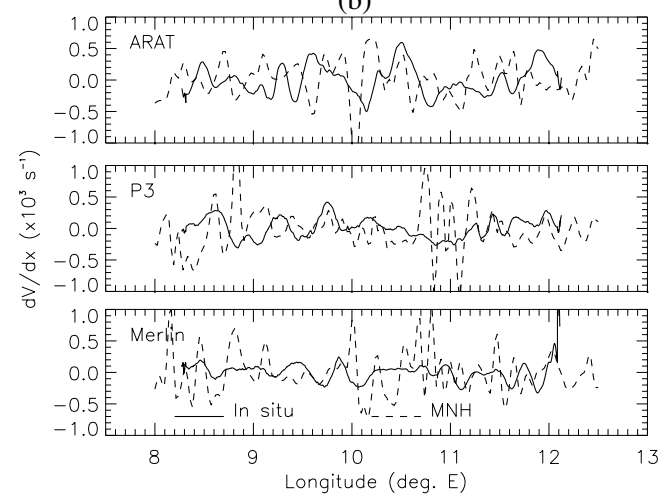

Figure 13. Vertical component of the vorticity (reduced to $\partial v / \partial x$ ) derived from in situ measurements (solid line) and Meso-NH (MNH; dashed line), using the finite-difference approach, at the ARAT, P-3 and Merlin flight levels, along (a) leg PO and (b) leg NQ.

(a)

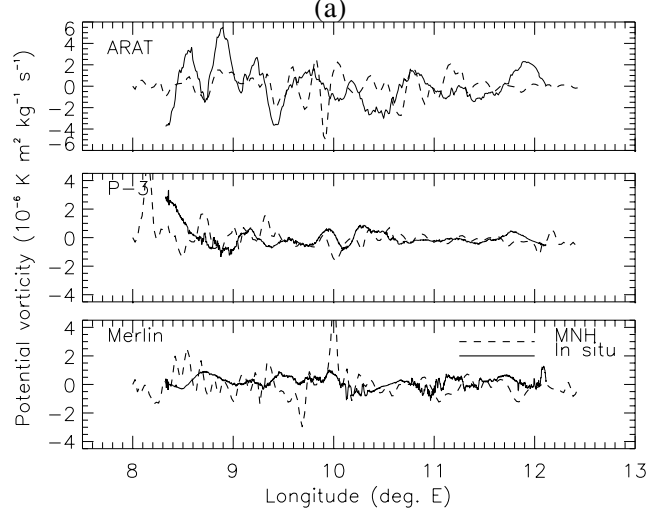

(b)

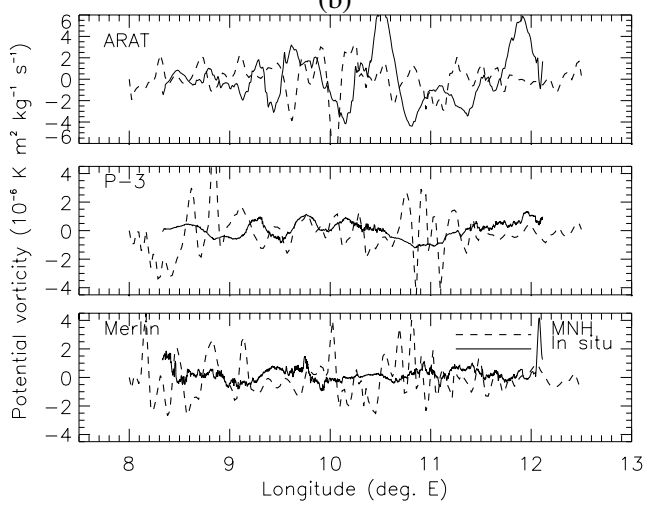

Figure 14. Simplified potential vorticity simulated by Meso-NH (MNH; dashed line) and computed from in situ measurements using Eq. (3) (solid line) along (a) leg PO and (b) leg NQ at the ARAT, P-3 and the Merlin flight levels.

of the vertical vorticity modulations derived experimentally and from Meso-NH are comparable over leg PO (but not over leg NQ), the correlation between the two is extremely weak. Hence, noticeable differences in PVB2 position along the legs are to be expected between experimentally derived and model-derived PVB2s at all levels.

A comparison of SPV simulated by Meso-NH and computed from in situ measurements using the simplified Eq. (3) along legs PO and NQ is shown in Fig. 14. At the lower two levels, the amplitude of the simulated SPV (characterised by the standard deviation of the SPV over a leg) is larger than the experimentally derived one. Conversely, at the ARAT flight level, the amplitude of the observed SPV is larger. No conclusive assessment can be made on the agreement in terms of the scale of the oscillations. The details of the structure of the SPV field simulated with Meso-NH are found to be different from the observations (i.e. the location of observed maxima and minima of SPV did not match their simulated counterparts when comparing exact values at particular points) due to the fact that the correspondence between observed and modelled velocity and potential temperature fields was not good enough to expect good correspondence between observed and modelled differentiated quantities such 
as vorticity and potential temperature gradient. The model/data comparison is further complicated by the fact that PV production in models such as Meso-NH is sensitive to parametrized processes (such as surface drag) and internal diffusion, and numerical processes, such as model filters. In such conditions, even fair agreement between observed and simulated SPV fluctuations is probably out of our grasp, so we consider that it is not worthwhile pushing model/data comparisons any further.

The only conclusive assessment that can be made from this study is that in situ measurements show that coherent PVB2s do exist downstream of the complex Alpine terrain since observations show oscillations between positive and negative values of $\mathrm{SPV}$, as expected from the simulations.

\section{SUMMARY AND CONCLUSION}

The structure of the PVBs forecast by MC2 during a northerly föhn event (during IOP 15 of the MAP SOP) has been investigated using analyses based on numerical simulations (using Meso-NH), and in situ measurements from three aircraft flying below the Alps crestline (at 2700, 1500 and $600 \mathrm{~m}$ ) along two $350 \mathrm{~km}$ east-west oriented legs, designed to be approximately perpendicular to the northerly synoptic flow. The main results are summarized below:

- $\quad$ The basic data-model comparison, back-trajectory and tracer release analyses showed that the jet/wake structure of the flow above the Po valley could be reasonably identified with the mountain pass/peak distributions.

- In situ measurements showed that coherent PVB2s do exist downstream of the complex Alpine terrain, since observations show oscillations between positive and negative values of SPV, as expected from the simulations. Due to increasing lee-side flow curvature with decreasing altitude (caused by flow splitting at the scale of the Alps), the experimentally derived SPV was compared to its simulated counterpart. (The SPV in the model was computed using the same basic equation describing a simplified form of the PV). The details of the structure of the SPV field simulated using Meso-NH was found to be different from the observations. The locations of observed maxima and minima of SPV did not match their simulated counterparts (when comparing exact values at particular points) because the correspondence between observed and modelled velocity and potential temperature fields was not good enough to expect good correspondence between observed and modelled differentiated quantities such as vorticity and potential temperature gradient, since less-reliable shorter-scale features are thereby accentuated. Parametrized processes (such as surface drag and internal diffusion) and numerical processes (such as model filters), to which PV production mechanisms are sensitive and whose role is difficult to assess, also contribute to the poor agreement between observed and modelled SPV fluctuations.

- Analysis of the PV terms conducted with Meso-NH indicated that the approach designed to capture the PV structure experimentally (i.e. the computation of the PV based on in situ measurements made at three flight levels) was valid only at the highest (ARAT) flight level, due to increasing flow curvature with decreasing altitude in the wake south of the Alps. This analysis also showed that, at the ARAT flight level, the position of the PVB2s along the leg was controlled by the vertical component of vorticity, whereas the amplitude of the PVB2s was controlled by the vertical gradient of potential temperature. 
- Simulations suggest that low-level gravity-wave breaking is the main mechanism responsible for the formation of the elongated PVB2 modelled/observed over the Po valley.

Low-level PVBs generated downstream of the Alps have been shown to contribute to the deepening of Alpine lee cyclones (Äbischer and Schär 1998). Recently, Flamant (2003) discussed the influence of Alpine lee cyclogenesis on ABL structure and air-sea exchanges over the western Mediterranean during a mistral event. He showed that the strength and direction of the mistral over the Gulf of Lion was controlled by the multistage evolution of the associated Alpine lee cyclone. Mistral-related cold-air outbreaks over the western Mediterranean are frequently associated with important surface heat losses to the atmosphere in the winter. Hence, provided that PVB features are as ubiquitous in the atmosphere as they are in numerical simulations, they could play a role in the Earth's energy balance at the regional scale, in a region (the Mediterranean) key to climate studies. However, to assess the role of PVB on the energy balance, further investigations need to be conducted on the sensitivity of PV production in models such as Meso-NH to parametrized processes such as surface drag and internal diffusion, and numerical processes, such as model filters. The operations conducted during the MAP SOP offered the first integrated (i.e. modelling and experimentation) attempt for progress towards a better understanding of the physical impact of PVBs. Future experimental studies conducted on PVB2s downstream of complex terrain should be designed to measure all components of the PV and should include a combination of airborne active remote sensing instruments, which can provide high spatio-temporal 3D fields of key variables such as wind, water vapour mixing ratio and temperature.

\section{ACKNOWLEDGEMENTS}

We would like to express our thanks to the crews of the P-3, ARAT and Merlin for their support and assistance in making the PVB mission a success. Special thanks to Didier Bruneau, Vincent Trouillet and Pascal Genau of Service d'Aéronomie; Frederic Blouzon, Abdel Abchiche, Nadir Amarouche, Guy Pennazzi, Christian Allet, Noël Grand, André Gribkof and Bernard Sinardet of the Technical Division of the Institut National des Sciences de l'Univers (INSU), and Daniel Damien and JeanLuc Pilotto of the Institut Géographique National. Many thanks to Paul Neiman (NOAA/Environmental Technology Laboratory), the two anonymous reviewers, and associate editor Nigel Wood for comments and suggestions that led to a significant improvement of this paper. Special thanks to Peggy Frazier Doviak (NOAA) for help with editing the manuscript.

This research has been funded by the Centre National de Recherche Scientifique through the Programme Atmosphère Océan à Méso-échelle, the INSU and the Centre National d'Études Spatiales. Computational resources were provided by the Institut du Développement et des Ressources en Informatique Scientifique (under project 030569CP1).

\section{APPENDIX}

\section{Gradient computation using the finite-difference approach}

In Eq. (3), the gradients involving $\partial / \partial x$ have been computed based on the finite differences of $v$ and $\theta$ between two consecutive data points (along a given leg, either PO or NQ). Similarly, the gradients involving $\partial / \partial z$ in Eq. (3) have been computed based on 

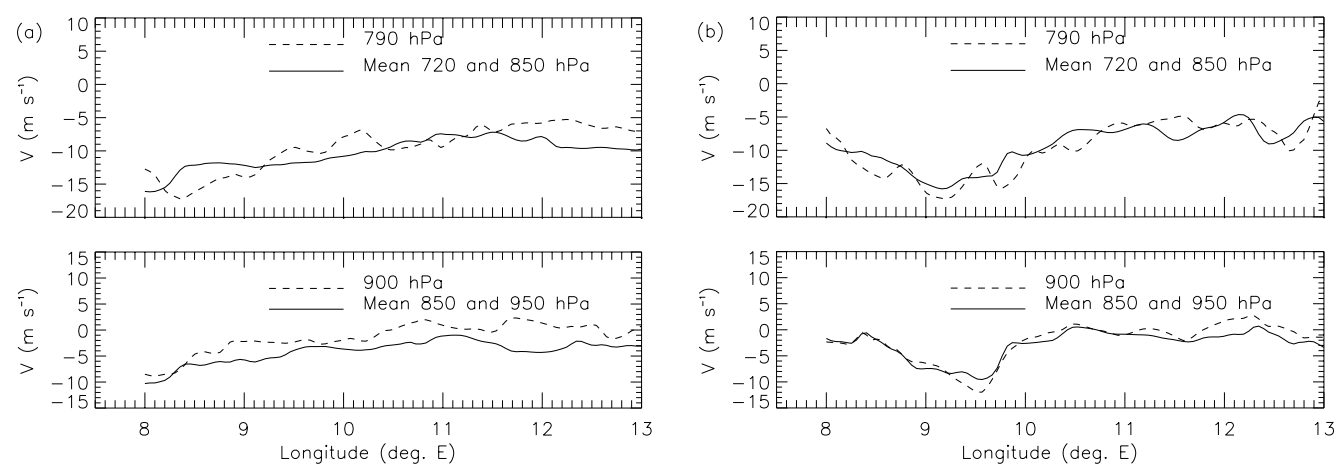

Figure A.1. Comparison of the north-south component of the wind simulated by Meso-NH (dashed line) at $790 \mathrm{hPa}$ (upper panel) and $900 \mathrm{hPa}$ (lower panel) with the means of such components (solid line) at 850 and $720 \mathrm{hPa}$ (upper) and 950 and $850 \mathrm{hPa}$ (lower) for (a) leg PO and (b) leg NQ.

the finite differences of $v$ and $\theta$ between the Merlin and ARAT flight levels. A crucial implicit assumption here is that the aircraft have operated in a coordinated vertically stacked fashion. This was the case, as the fastest aircraft (the P-3) adjusted its speed to match that of the slower aircraft. (The ARAT and the Merlin fly at approximately the same speed.)

Computing vertical gradients with a finite-difference approach using three aircraft levels implies that PV be computed at two intermediate levels (say 900 and $790 \mathrm{hPa}$ ). This also implies that variables needed to compute horizontal gradients $\partial / \partial x$ be interpolated to those intermediate levels. This can be problematic as discussed below. The alternative would be to compute PV at the three flight levels using 'one-sided' vertical derivatives (i.e. to assume that the gradient computed using data from two flight levels was representative of the vertical derivative at either of these flight levels). This also may raise some difficulties. In the following, we review and illustrate the pros and cons of each approach.

Because the lee-side flow curvature increases with decreasing altitude (Fig. 6), fields averaged from two flight levels onto an intermediate one might not be representative of the 'true' field on that intermediate level. This is illustrated in Fig. A.1 with the north-south component of the horizontal wind, $v$, extracted from Meso- $\mathrm{NH}$ along both legs PO and NQ. The data extracted at 720 and $850 \mathrm{hPa}(850$ and $950 \mathrm{hPa})$ have been averaged and compared to the data extracted at 790 (900) hPa. From this figure, structural differences are evident which will lead to even larger discrepancies whenever horizontal gradients are computed.

A balloon sounding launched from Milano at 1200 UTC and a sounding performed by the Merlin shortly after taking off from Milano at approximately the same time (Fig. A.2(a)) were used to estimate the vertical variability of the term $\partial \theta / \partial z$ (Fig. A.2(b)). Even though these profiles were acquired at roughly the same time, important differences exist between the two, which are thought to reflect the spatial inhomogeneities in the thermodynamics of the flow over the Po valley. (The balloon drifted south of Milano while the Merlin made a tight spiral sounding at the location shown in Fig. 2). Noticeably, a cold pool was observed on the balloon sounding, but this did not appear on the Merlin sounding. The Merlin sounding also exhibited higher potential temperatures, by 1 to $4 \mathrm{~K}$. This is likely due to the wrapping of the front around the western tip of the Alps; it seems that the Merlin and the balloon launched at Milano sampled air masses on different sides of the front, the Merlin being on the warmer side. 

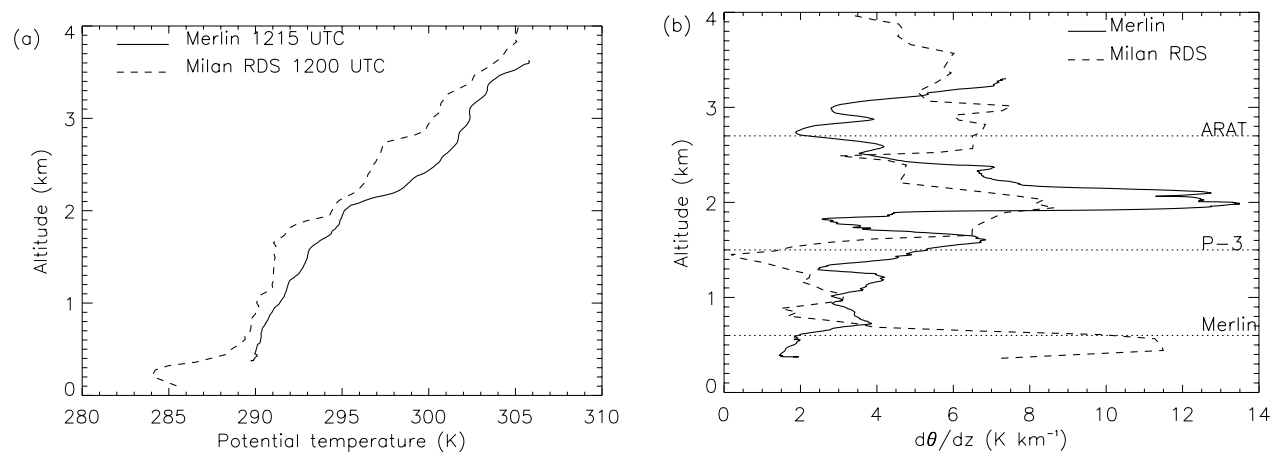

Figure A.2. Profiles of (a) potential temperature derived from the balloon sounding (dashed line) launched from Milano at 1200 UTC on 8 November 1999 and from Merlin measurements (solid line) shortly after taking off from

Milano at approximately the same time, and (b) potential temperature gradients derived from these soundings.

This could also explain why the Merlin did not sample the cold pool observed further to the east at Milano. The stratification of the flow as sampled by both the Merlin and the balloon sounding (i.e. the location of the temperature inversions) was also quite different.

The term $\partial \theta / \partial z$ was observed to vary substantially, both in the vertical and between profiles. The Merlin and balloon data showed that the average $\partial \theta / \partial z$ derived from measurements at 2700 and $1500 \mathrm{~m}$ was not at all representative of the value of $\partial \theta / \partial z$ at an intermediate level, say $2100 \mathrm{~m}\left(4\right.$ versus $8.5 \mathrm{~K} \mathrm{~km}^{-1}$ for balloon data, and 4.5 versus $11 \mathrm{~K} \mathrm{~km}^{-1}$ for Merlin data). Hence, computing PV on an intermediate level assuming $\partial \theta / \partial z$ can be estimated using the ARAT and P-3 measurements would lead to substantial errors. According to the balloon sounding, this is also true of the estimate that can be made at an intermediate level, say $1100 \mathrm{~m}$, using the Merlin and P-3 measurements. On the other hand, the $\partial \theta / \partial z$ profile obtained from the Merlin sounding showed a lot less variability below $1500 \mathrm{~m}$.

In conclusion, it appears that computing PV at intermediate levels might lead to substantial errors due to inaccurate estimates of the $v$ and $\theta$ fields. As discussed in section 6(c)(ii), the width of the PVB2s is controlled by terms involving $\partial / \partial x$, while their amplitude is controlled by the terms involving $\partial \theta / \partial z$. One should be careful when computing PV from two levels, $L_{1}$ and $L_{2}$, at an intermediate level, $L_{\mathrm{i}}$, because the along-leg fluctuations of quantities such as $\left(\theta_{2}+\theta_{1}\right) / 2$ and $\left(v_{2}+v_{1}\right) / 2$ do not necessarily match those of $\theta_{\mathrm{i}}$ and $v_{\mathrm{i}}$ as demonstrated using Meso-NH outputs for $v$ (Fig. A.1) and $\theta$ (not shown). Therefore, the experimentally derived PV was computed at the aircraft flight levels. The vertical gradients (i.e. $\partial / \partial z$ ) along legs PO and NQ were computed as: (i) $\left(\theta_{2700}-\theta_{1500}\right) / 1200$, (ii) $\left(\theta_{2700}-\theta_{600}\right) / 2100$ and (iii) $\left(\theta_{1500}-\theta_{600}\right) / 900$, for the ARAT, P-3 and Merlin levels, respectively.

\section{REFERENCES}

Äbischer, U. and Schär, C.

Bechtold, P., Bazile, E.,

Guichard, F., Mascart, P. and

Richard, E.
1998 Low-level potential vorticity and cyclogenesis in the lee of the Alps. J. Atmos. Sci., 55, 186-207

2001 A mass flux convection scheme for regional and global models. Q. J. R. Meteorol. Soc., 127, 869-886 
Benoit, R., Schär, C., Binder, P., Chamberland, S.,

Davies, H. C., Desagné, M., Girard, C., Keil, C.,

Kouwen, N., Lüthi, D.,

Maric, D., Müller, E.,

Pellerin, P., Schmidli, J.,

Schubiger, F., Schwierz, C.,

Sprenger, M., Walser, A.,

Willemse, S., Yu W. and

Zala, E

Binder, P. and Schär, C.

Bougeault, P., Binder, P. and

Kuettner, J.

Bougeault, P., Binder, P., Buzzi, A., 2001

Dirks, R., Houze, R.,

Kuettner, J., Smith, R. B.,

Steinacker, R. and Volkert, $\mathrm{H}$.

Chalon, J.-P., André, M.

Brenguier, J. L., Druilhet, A.,

Gayet, J. F., Flamant, P.,

Guillemet, B., Hauser, D.,

Kerr, Y., Pelon, J., Ravaut, M. and Tanré, D.

Cuxart, J., Bougeault, P. and

Redelsperger J.-L.

Davies, L. A. and Brown A. R.

Epifanio, C. C. and Durran, D. R.

Flamant, C.

Gheusi, F. and Stein, J.

Grubisić, V.

Jiang, Q., Smith, R. B. and Doyle, J. 2003

Jorgensen, D. P.

1984

Jorgensen, D. P. and LeMone, M. A. 1989

Lafore, J. P., Stein, J., Asencio, N., 1998 Bougeault, P., Ducrocq, V., Duron, J., Fischer, C., Hereil, P., Mascart, P., Pinty, J. P., Redelsperger, J. L., Richard, E. and

Vila-Guerau de Arellano, J.

Lambert, D. and Durand, P.

Mallet, I., Cammas, J. P., Mascart, P. and Bechtold, P.

998

The real-time ultrafinescale forecast support during the Special Observing Period of the MAP. Bull. Am. Meteorol. Soc., 83, 85-109

1996 nonlinear viscous simulations. J. Atmos. Sci., 59, 1166-1181

Alpine lee cyclogenesis influence on air-sea heat exchanges and marine atmospheric boundary layer thermodynamics over the Western Mediterranean during a Tramontane/Mistral event. J. Geophys. Res., 108, 8057, doi:10.1029/2001JC001040

Lagrangian description of airflows using Eulerian passive tracers. Q. J. R. Meteorol. Soc., 128, 337-360

'Structure of the wake north of the Alps: PV banners during an episode of deep south foehn'. Pp. 180-183 of proceedings of AMS Ninth Conference on Mesoscale Processes, American Meteorological Society, Boston, USA

Bora-driven potential vorticity banners over the Adriatic. $Q . J . R$. Meteorol. Soc., in press

The nature of the mistral: Observations and modelling of two MAP events. Q. J. R. Meteorol. Soc., 129, 857-875

Mesoscale and convective-scale characteristics of mature hurricanes. Part I: General observations by research aircraft J. Atmos. Sci., 41, 1268-1285

Vertically velocity characteristics of oceanic convection. J. Atmos. Sci., 46, 621-640

The Meso-NH atmospheric simulation system. Part I: adiabatic formulation and control simulation. Ann. Geophys., 16, 90-109

Aircraft to aircraft intercomparaison during SEMAPHORE. J. Geophys. Res., 103, 25109-25123

1999 Effects of cloud diabatic heating on the early development of the FASTEX IOP17 cyclone. Q. J. R. Meteorol. Soc., 125, 34393467 
Matejka, T. and Lewis, S. A.

1996

Morcrette, J.-J.

1991

Nance, L., Attié, J.-L., Bénech, B. 2000 Colman, B. R. Doyle, J. D., Flamant, C., Grubisić, V., Pelon, J., Ralph, F. M., Rotunno, R., Schär, C., Smith, R. B. and Steinacker, R. Noilhan, J. and Planton, S.

Rotunno, R., Grubisić, V. and Smolarkiewicz, P. K.

Schär, C.

2000

Schär, C. and Durran, D.

Schär, C., Sprenger, M., Luthi, D., Jiang, Q., Smith, R. B. and Benoit, R.

Schneider, T., Held, I. M. and Garner, S. T.

Smith, R. B.

Smith, R. B. and Grubisić, V.

Smith, R. B., Gleason, A. C., Gluhosky, P. A. and Grubisić, V.

Stein J., Richard, E., Lafore, J. P., Pinty, J. P., Asencio, N. and Cosma, $\mathrm{S}$.

Thorpe, A. J., Volkert, H. and Heimann, D.
Improving research aircraft navigation by incorporating INS and GPS information in a variational solution. J. Atmos. Ocean. Tech., 14, 495-511

Radiation and cloud radiative properties in the European center for medium range weather forecasts forecasting system. J. Geophys. Res., 96, 9121-9132

'Observations of potential vorticity banners during the Mesoscale Alpine Programme'. Pp. 43-48 of Ninth Conference on Mountain Meteorology, American Meteorological Society, Aspen, CO, 7-11 August 2000

1989 A simple parameterization of land surface processes for meteorological models. Mon. Weath. Rev., 117, 536-549

1999 Vorticity and potential vorticity in mountain wakes. J. Atmos. Sci., 56, 2796-2810

1993 A generalization of Bernoulli's theorem. J. Atmos. Sci., 50, 14371443

1997 Vortex formation and vortex shedding in continously stratified flows past isolated topography. J. Atmos. Sci., 54, 535-554

2003 Structure and dynamics of an Alpine potential vorticity banner. Q. J. R. Meteorol. Soc., 129, 857-876.

2003 Boundary effects in potential vorticity dynamics. J. Atmos. Sci., 60, 1024-1040

1989a Hydrostatic airflow over mountains. Adv. Geophys., 31, 1-41

1989b Comment on 'Low Froude number flow past three-dimensional obstacles. Part I: Baroclinically generated lee vortices.' J. Atmos. Sci., 46, 3611-3613

1993 Aerial observations of Hawaii's wake. J. Atmos. Sci., 50, 37283750

1997 The wake of St Vincent. J. Atmos. Sci., 54, 606-623

2000 High-resolution non-hydrostatic simulations of flash-flood episodes with grid-nesting and ice-phased parameterization, Meteorol. Atmos. Phys., 72, 203-221

1993 Potential vorticity of flow along the Alps. J. Atmos. Sci., 50, 15731590 